\title{
On the Transition of Contrails into Cirrus Clouds
}

\author{
F. Schröder,* B. Kärcher, * C. Duroure, + J. Ström,\# A. Petzold, $*$ J.-F. Gayet, ${ }^{+}$ \\ B. Strauss, * P. Wendling, * and S. Borrmann\& \\ * Institut für Physik der Atmosphäre, DLR, Oberpfaffenhofen, Germany \\ + Laboratoire de Meteorologie Physique, Université Blaise Pascal, Clermont-Ferrand, France \\ \# Meteorologiska Institutionen, Stockholms Universitet, Stockholm, Sweden \\ \& Institut für Stratosphärenchemie, ICG-1, Forschungszentrum Julich, Germany
}

(Manuscript received 9 September 1998, in final form 2 March 1999)

\begin{abstract}
In situ observations of the microphysical properties of upper-tropospheric contrails and cirrus clouds have been performed during more than 15 airborne missions over central Europe. Experimental and technical aspects concerning in situ characterization of ice clouds with the help of optical and nonoptical detection methods (preferably FSSP-300 and Hallet-type replicator) are addressed. The development of contrails into cirrus clouds on the timescale of $1 \mathrm{~h}$ is discussed in terms of a representative set of number densities, and size distributions and surface area distributions of aerosols and cloud elements, with special emphasis on small ice crystals (diameter $<20 \mu \mathrm{m})$. Contrails are dominated by high concentrations $\left(>100 \mathrm{~cm}^{-3}\right)$ of nearly spherical ice crystals with mean diameters in the range 1-10 $\mu \mathrm{m}$. Young cirrus clouds, which mostly contain small regularly shaped ice crystals in the range $10-20-\mu \mathrm{m}$ diameter and typical concentrations $2-5 \mathrm{~cm}^{-3}$, have been observed. Measurement results are compared to simple parcel model calculations to identify parameters relevant for the contrail-cirrus transition. Observations and model estimates suggest that contrail growth is only weakly, if at all, affected by preexisting cirrus clouds.
\end{abstract}

\section{Introduction}

Ice clouds in the upper troposphere cover about 20\%$30 \%$ of global surface and play an important role in the earth's radiation budget, with a substantial impact on climate. Their radiative properties strongly depend on microphysical characteristics such as number concentration, crystal shapes, size distribution, and the crystal diameter. Small ice crystals below $20-\mu \mathrm{m}$ diameter would strongly affect radiative transfer through a cloud if they were present in larger numbers. However, in situ measurements of crystal distributions in that size range have previously been rare and frequently found unreliable (e.g., Platt and Spinhirne 1989; Heymsfield and McFarquhar 1996; Gayet et al. 1996). Only a few recent case studies demonstrate the existence of larger numbers of ice cloud particles below about a mean diameter $D_{m}$ $=30 \mu \mathrm{m}$ (e.g., Noone et al. 1993; Ström et al. 1994, 1997; Crutzen and Ramanathan 1996; Goodman et al. 1998; Heymsfield et al. 1998a,b). Thus, model parameterizations of cirrus cloud radiative properties still suffer from the lack of empirical information about the small ice crystal range (e.g., Fu and Liou 1993).

Corresponding author address: Franz Schröder, Institut für Physik der Atmosphäre, Postfach 1116, D-82234 Weßling, Germany.

E-mail: franz.schroeder@dlr.de
Besides natural cirrus clouds, contrails resulting from jet aircraft exhausts have become of considerable interest with respect to the question whether and in which way aviation emissions could modify upper-tropospheric ice cloud microphysics on regional and global scales (e.g., Friedl 1997; Brasseur et al. 1998). Aircraft exhaust may trigger cloud formation in two ways, either directly or indirectly. In the direct case, a contrail forms immediately behind the aircraft. This requires a special thermodynamic state of the atmosphere, especially low $(<230 \mathrm{~K})$ temperatures at typical flight altitudes $(\sim 250$ hPa) (e.g., Schumann 1996). After a short (about 1 s) initial growth stage (Kärcher et al. 1996), the contrail will evaporate within tens of seconds if the air is dry. In contrast, contrail growth will continue in background air that is supersaturated with respect to ice. Eventually, the line-shaped contrail may transform into a cirrus cloud, as demonstrated by satellite observations (Schumann and Wendling 1990; Minnis et al. 1998; Mannstein et al. 1999). The indirect way can occur when aging aircraft exhaust, consisting of an internal mixture of black carbon soot and liquid volatile aerosols (mainly composed of $\mathrm{H}_{2} \mathrm{SO}_{4} / \mathrm{H}_{2} \mathrm{O}$ ), leads to the nucleation of ice crystals and, hence, the formation of cirrus clouds, where no cloud would have formed in absence of aircraft (Jensen and Toon 1997; DeMott et al. 1997; Kärcher et al. 1998). This may occur when aircraft exhaust particles 
have an increased ice-forming ability compared to background particles.

Although several model studies concerning the formation and evolution of cirrus clouds and contrails have been performed (Starr and Cox 1985; Heymsfield and Sabin 1989; Sassen and Dodd 1989; Jensen et al. 1994; De Mott et al. 1994; Kärcher et al. 1996; Gierens 1996; Gierens and Jensen 1998), the detailed processes are far from being understood by now, mainly due to the few observational data available. New in situ and remote sensing case studies on single contrails have recently been reported (Petzold et al. 1997; Gayet et al. 1998; Baumgardner et al. 1998; Baumgardner and Gandrud 1998; Goodmann et al. 1998; Spinhirne et al. 1998; Minnis et al. 1998; Lawson et al. 1998; Heymsfield et al. 1998b). Experimental in situ characterizations alone will possibly not be sufficient for a complete understanding of cirrus formation, so that accompanying laboratory studies will be required.

This study summarizes a comprehensive set of recent in situ observations of cirrus and contrail ice crystal size distributions, which have been performed using a combination of optical and nonoptical detection methods. Ice clouds and contrails are examined that are representative for the midlatitude Northern Hemisphere, typically at temperatures between $-50^{\circ}$ and $-60^{\circ} \mathrm{C}$ and altitudes between about 9 and $12 \mathrm{~km}$. We have assembled empirical information into a compact, exemplary dataset, illustrating contrail and cirrus microphysical properties down into the submicron range. The observations may also be helpful to develop a parameterization of the effective diameter of contrails for use in climate models. In addition to the in situ data, we discuss the transformation of contrails into cirrus clouds by means of a simple parcel model. The numerical study identifies atmospheric variables that control the contrail development, and explores the respective parameter ranges needed to match the observations. Such information is a necessary first step in assessing the radiative impact of contrails and contrail-induced cirrus clouds.

\section{Experimental}

\section{a. Instrumentation}

During the airborne experiments Sulfur 4 and Sulfur 5, Contrail, and Aerocontrail in 1996-97, the DLR research aircraft Falcon was equipped with changing combinations of instrumentation for aerosol and cloud research (compiled in Table 1) to measure, among other topics, the microphysical structure of jet exhaust plumes, contrails, and cirrus clouds in the tropopause region (Schumann et al. 1996; Petzold et al. 1997). Optical spectrometers FSSP-300, FSSP-100ER and OAP2DC, PCASP-100X, and a polar nephelometer (Crepel et al. 1997; Gayet et al. 1998), all mounted at outside wing stations of the aircraft, were used to determine aerosol and ice crystal size distributions in the diameter range from nominally $0.1 \mu \mathrm{m}$ up to about $800 \mu \mathrm{m}$.

The FSSP and OAP spectrometers (e.g. Baumgardner et al. 1985, 1992, 1996; Baumgardner and Spowart 1990) allow an almost unperturbed in situ detection of aerosol and cloud elements, the first by forward light scattering (diameter range $0.3-100 \mu \mathrm{m}$ ), the latter by two-dimensional projection of particle shadow images $(20-750 \mu \mathrm{m})$. During most of the experiments the FSSP-100ER has been operated in the "extended range" (6-98 $\mu \mathrm{m})$ to achieve an optimum range overlap with the FSSP-300 and OAP-2DC instruments. The PCASP (Strapp et al. 1992) aerodynamically focuses an aerosol sample volume shielded by a dry, warm sheath airflow into a He-Ne laser beam where it is classified by the scattered power. This instrument evaporates the water fraction of the aerosol prior to detection $(\mathrm{RH}<10 \%)$ and the measured size commonly referred to as the "dry" size of the aerosol within the diameter range $0.1-$ $3 \mu \mathrm{m}$.

Two nonoptical methods have been applied to achieve additional information on crystal shape, size, and number. 1) A Hallet-type replicator (REP) yielded impact images of ice crystals (replica) on 16-mm film material (Hallet 1976) for crystal diameters above about $1 \mu \mathrm{m}$. Although this instrument suffers from not-yet-quantified aerodynamic particle losses below about $3 \mu \mathrm{m}$ and from breakup effects of large ice particles, it allows rough estimates of crystal number and size distribution over the FSSP range. 2) A counterflow virtual impactor (CVI; Noone et al. 1985; Noone et al. 1993; Anderson et al. 1993; Ström and Heintzenberg 1994; Ström et al. 1994), which inertially separates supermicron particles from the surrounding atmosphere, has been operated in the diameter range of $5 \mu \mathrm{m}$ to about $80 \mu \mathrm{m}$. For interpretation of CVI data, one single condensation nucleus per ice crystal is assumed and the actual concentration of ice crystals is determined by individually counting their residues.

Various condensation nuclei counters (modified commercial CNCs; Schröder and Ström 1997; Mertes et al. 1995) have been operated to determine the integral condensation nuclei (CN) number concentrations. Thermodynamic atmospheric parameters were deduced from the Falcon meteorological air sensor set as previously described by Busen et al. (1997). Namely, the reported ambient RH values have been monitored by several sensors, but mainly based on data from a cryogenic mirror with a relative measurement uncertainty of at least $\pm 5 \%$. Unless stated otherwise, all concentrations are reported as ambient atmospheric number densities per cubic centimeter of air. Several measurements of contrails produced by commercial aircraft types have been performed. More detailed studies have been carried out behind the DLR twin-engine research aircraft Attas (Petzold et al. 1997). We select representative cases from our dataset that are most completely documented and that help to illustrate the microphysical evolution of 
TABLE 1. Listing of applied instrumentation during the Contrail, Aerocontrail, and Sulfur 5 experiments.

\begin{tabular}{llc}
\hline \hline Short name & \multicolumn{1}{c}{$\begin{array}{c}\text { Nominal diameter } \\
\text { range }(\mu \mathrm{m})\end{array}$} \\
\hline OAP-2DC & PMS Two-Dimensional Cloud Optical Array Probe & 20-750 \\
FSSP-100ER & PMS Extended Range Forward Scattering Spectrometer Probe & $0.4-20$ \\
FSSP-300 & PMS Aerosol Forward Scattering Spectrometer Probe & $0.12-3$ \\
PCASP-100X & PMS Passive Cavity Aerosol Spectrometer Probe & 5-80 \\
REP & Hallet-Type Replicator & \\
CVI & Counterflow Virtual Impactor & \\
CNC & Condensation Nucleus Counter, Type TSI 3010 & \\
\hline
\end{tabular}

contrails in time. The dataset is also used to compare contrails with natural cirrus and to document contrails embedded in cirrus clouds.

\section{b. Data evaluation and interpretation}

Since the emphasis of this study lies on small ice crystals, it is important to overcome the uncertainties of particle sizing by FSSP laser spectrometers, especially for the key instrument FSSP-300 (Baumgardner et al. 1992), which covers the size range most sensitive to ambiguities in light scattering according to the Mie theory. The FSSP-300 raw information obtained in contrail and cirrus environments has been treated in the following manner as the result of measurements with a forward-backward scattering instrument [Multiangle Aerosol Spectrometer Probe (MASP); Baumgardner et al. 1996] and comparisons with FSSP-100, PCASP, and the REP. The overall size resolution of the FSSP-300 has been reduced. The size bin limits related to supermicron particles have been regrouped for a refractive index of 1.33 corresponding to water, and the channel bin limits related to the submicron range according to $n=1.46+0.05 i$. Channels $5-12$ have been summed up. The remaining spectral resolution contains 13 size intervals between $0.4 \mu \mathrm{m}$ and about $20 \mu \mathrm{m}$, with interval size limits of $0.36,0.41,0.46,0.52,0.58,1.2,2$, $3.1,5.2,7.1,10,11,13$, and $21 \mu \mathrm{m}$. Therefore, we consider the changes of refractive index between fine and coarse mode of particle ensembles that can be expected in a contrail environment. This data treatment is in agreement with recent field measurements with the MASP (Kuhn et al. 1998), which indicate large fractions of submicron particles with refraction indices above 1.46 plus an absorbing component, both in contrails and in the background atmosphere. The FSSP-300-derived distributions are also consistent with recent microphysical simulations of contrail formation (Kärcher et al. 1998) and related experimental findings (Petzold et al. 1996; Schröder et al. 1998). Other concepts of regrouping FSSP-300 channel information, for example, by prescribing an ellipsoidal shape for the ice particles using the $T$-matrix method (Borrmann et al. 1996; S. Borrmann 1998, personal communication), have been followed as well, but did not cause major changes in the ice crystal spectra that would affect the conclusions of this work.
A dead-time correction (e.g., Baumgardner et al. 1985; Brenguier 1989; Brenguier et al. 1994) has been applied to the FSSP-300 data when concentrations exceeded about $800 \mathrm{~cm}^{-3}$. Following Baumgardner et al. (1992), the combined sampling losses of the FSSP-300 exceed $5 \%$ above about $500 \mathrm{~cm}^{-3}$. The dead-time corrections resulted in an increase of total concentrations up to a factor of about 2. Measurements carried out in very young plumes (plume age $<8 \mathrm{~s}$, characterized by very high crystal abundance) apparently suffer from higher underestimation, possibly much larger than a factor of 2. Further, coincidence effects on the particle spectra (e.g., Cooper 1988) are observed in such cases, but they do not seem to change the shape of the crystal spectra significantly. However, only two of the nearfield distributions presented are concerned here.

The FSSP-100ER has mostly been operated in the $6-98-\mu \mathrm{m}$ range, occasionally also in the $2-47-\mu \mathrm{m}$ range. The crystal concentrations observed in contrails and cirrus over these size ranges have been sufficiently low so that no coincidence or dead-time corrections have been applied. Even corrections for the relatively high true airspeed $\left(>160 \mathrm{~m} \mathrm{~s}^{-1}\right)$ during the measurements have neither been applied to FSSP-100 nor to FSSP300 data. According to Baumgardner and Spoward (1990), the velocity effect will be limited to about $20 \%$ intensity reduction in the probe's response, causing about 10\% systematical undersizing (Baumgardner et al. 1992). We are also aware that FSSP-100 instruments lose detection efficiency toward their lower size detection limit (Cooper 1988; Wendisch et al. 1996) and that this possibly holds even for the channels at the upper detection border. The OAP-2DC tends to underestimate particle concentrations in the lower channels, because diffraction effects are known to cause oversizing of particles with real diameters up to $100 \mu \mathrm{m}$ and an overestimation in channels for sizes larger than about 120 $\mu \mathrm{m}$ (e.g., Korolev et al. 1991, 1998). Another uncertainty of OAP-derived data in the diameter range up to $150 \mu \mathrm{m}$ arises from a reduction of the effective sample volume due to high true airspeeds, which has been the case performing the OAP on board the Falcon (at true airspeed around $180 \mathrm{~m} \mathrm{~s}^{-1}$ ). Recent work of Baumgardner and Korolev (1997) has been applied to the OAP spectra presented in section $3 \mathrm{~b}$. In certain cases we thus exclude the border-channel information of FSSP or OAP 
from the graphical illustrations of the crystal spectra. Spectral raw information from the OAP has been retrieved from a processing code previously discussed by Duroure et al. (1994). In summary, about 30\% error in concentration seems to be realistic for all optical instruments and discrepancies in the overlap ranges of the instruments within a factor 2 have thus been regarded as tolerable within the measurement uncertainties. For a more detailed review on the main Particle Measuring Systems (PMS) type of optical probes refer to Larsen et al. (1998) and Gayet et al. (1996).

Replica images from the REP film have been enlarged photographically and areas corresponding to exposure times of about $1 \mathrm{~s}$ have been analyzed manually by counting. For the cases where the sampling has been performed in contrails, the replica have been grouped into three to four size classes between 1, 5, 10, and 30 $\mu \mathrm{m}$. Counting has been repeated independently and the subjective results agreed well within $15 \%$. In a cirrus environment the evaluation of replica data is more problematic, because in the presence of ice crystals presumably larger than about 80-100 $\mu \mathrm{m}$, the REP suffers from crystal breakup and subsequent distortion of the measurement by the breakup products. Commonly, the impact of larger crystals can be clearly identified by a "crater"-shaped image on the substrate coating and the radial orientation of the fragments. Evaluating the number of such craters yields a rough estimate of the integral number concentration of cirrus ice crystals above about 80-100 $\mu \mathrm{m}$.

The age of a contrail —as long as fresh plumes up to about $20 \mathrm{~s}$ are investigated - has most commonly been determined by analysis of global positioning system data and/or video pictures of the heading aircraft, as described by Schröder et al. (1998). Contrail ages of typically 1-20 min were derived from the direct video recordings of the air traffic radar control monitoring at Munich Airport ATC. Such recordings were very helpful in determining contrail age with an accuracy of about $10 \mathrm{~s}$ and, further, in estimating a minimum age of unidentified contrails by investigating the time window ahead with respect to passing air traffic at the actual cruise level.

\section{Observations and discussion}

Contrails older than a few minutes proved to be difficult to sample in situ because such contrails, even if visible from far below or aloft, are in most of the cases difficult to recognize and thus to follow while flying on the same level. In most of the cases the optical contrast to the environment was very low. Following different jet aircraft during more than 60 occasions, contrails older than about $10-15$ min could only be identified and sampled in very few cases. This raises the question whether very low concentrations of upper-tropospheric ice crystals frequently occur under conditions that are also favorable for contrails to form and persist. Such "subvisible" cirrus clouds, although optically thin in the vertical, would cause much more optical depth on horizontal scales of several tenths of kilometers and could explain the poor contrast of aged contrails compared to their environment. A simple calculation shows that very few ice particles, $1 \mathrm{~L}^{-1}$ and $20 \mu \mathrm{m}$ in diameter, will cause a low optical thickness of $\delta=3 \times 10^{-5}$ throughout a $0.5-\mathrm{km}$-thick layer in the vertical, while $\delta$ easily passes the visibility threshold $(\delta=0.02)$ on a horizontal scale of less than $40 \mathrm{~km}$. Because the extinction coefficient of ice crystals increases in proportion to their geometric cross section, the presence of very few larger ice crystals in a widespread horizontal layer can strongly affect the optical identification of a contrail in situ. Future studies of aged contrails would therefore require a ground-based lidar support leading the aircraft through the cloud.

In this work we focus on contrail and cirrus properties derived from ice crystal spectra, which have commonly been achieved by flying inside and visually following the contrail. Since many of the structures discussed below have been fairly inhomogeneous and not widely spread, the spatial resolution of contrail properties turned out to be problematic. In fact, the geometrical structure of contrails of an age up to about 2 min (the end of the vortex phase) can be expected to be complicated and highly variable (e.g., Gerz and Holzäpfel 1999). Thus, the contrail ice crystal spectra presented are distributions averaged over time intervals of a few tenths of a second to typically a few seconds and mostly refer to the most dense contrail regions. Table 2 summarizes relevant information on all contrails and cirrus clouds discussed in the following sections. Besides aircraft types, plume age, temperature, and relative humidity, the different moments of the crystal distributions as deduced from the optical spectrometers are listed.

\section{a. Observations in contrails}

Figure 1 contains a representative selection of ice crystal number size distributions, which illustrates different pathways of contrail evolution: evaporation of short-lived contrails in dry air as well as growth of persistent contrails under ice-supersaturated conditions. Fresh contrails in the jet phase start developing from a narrow ice crystal mode close to $1-\mu \mathrm{m}$ mean diameter. The distribution "AT" represents such a typical fresh contrail of the Attas aircraft a few seconds after emission. Such a primary ice crystal mode is mainly composed of jet engine-emitted ice water nucleated on exhaust aerosol (Kärcher et al. 1996), as experimentally documented by Petzold et al. (1997). Note the difference between the in situ FSSP-300 spectrum AT and the "dry nonvolatile emissions" (mainly soot particles) as represented by distribution $\mathrm{S}$. The latter represents a combination of PCASP and FSSP-300 spectra obtained under noncontrail-forming conditions in the near field behind the Attas aircraft at distances comparable to AT. 


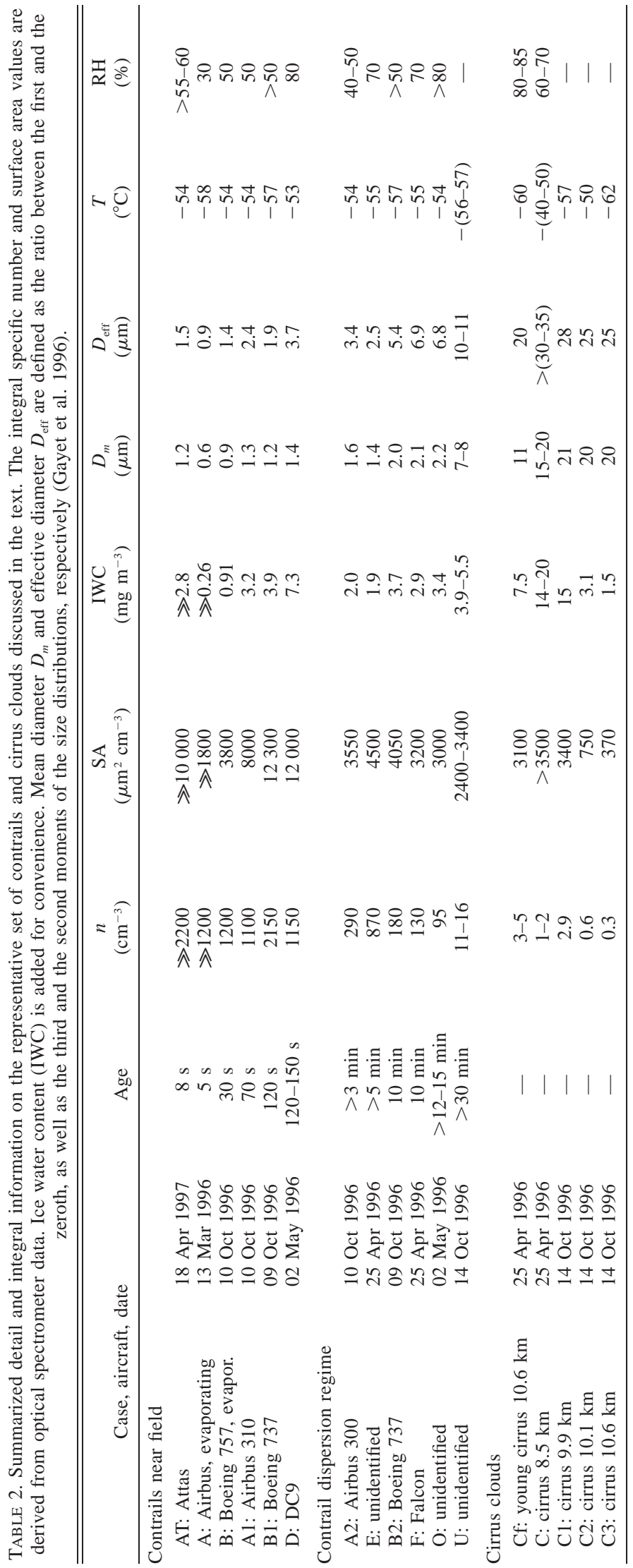




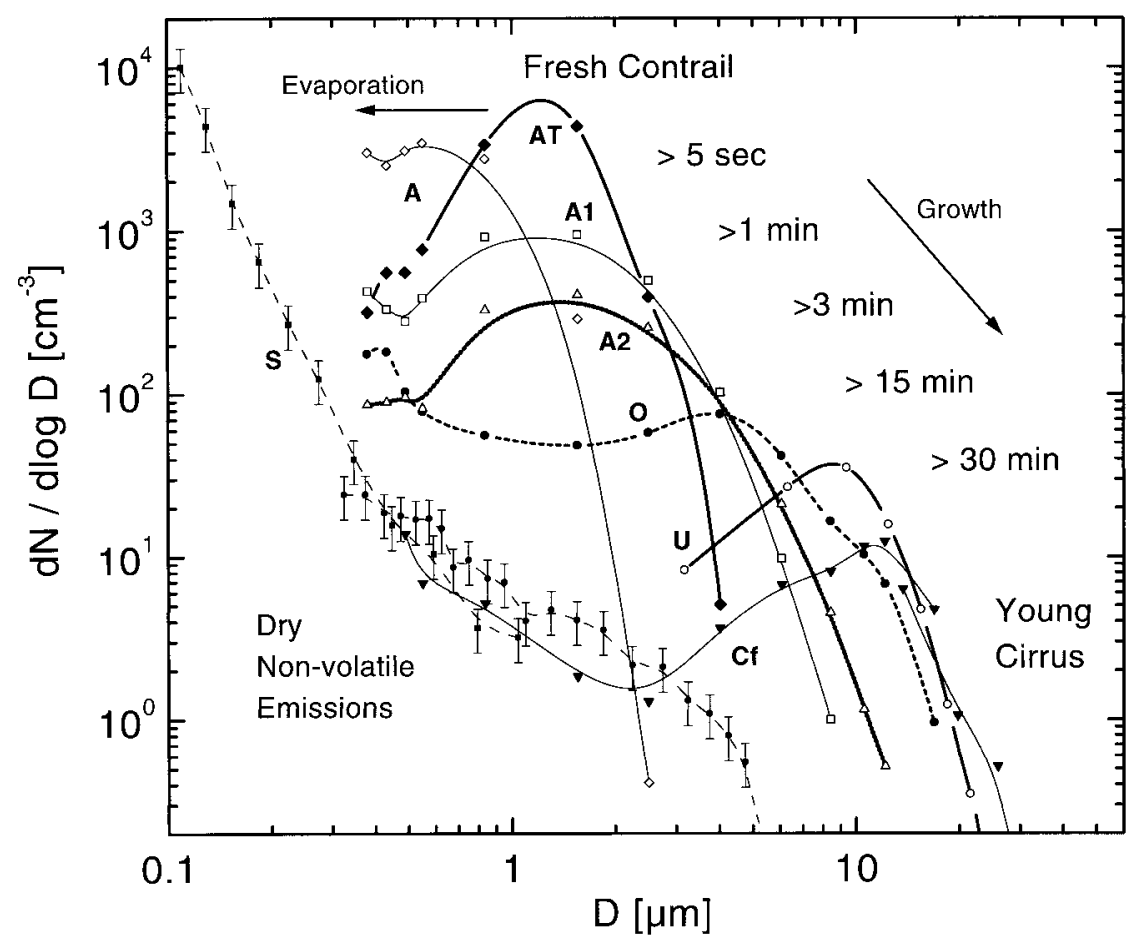

FIG. 1. Representative selection of particle concentrations illustrating the transition of contrails into cirrus clouds. Contrail cases: AT (solid diamonds), A (open diamonds, solid line), A1 (open squares, solid line), A2 (open triangles, bold dotted), O (solid circles, dashed), and U (open circles, bold line); case Cf: young cirrus cloud (solid triangles, solid line); case S: dry exhaust jet aircraft emissions (combined PCASP and FSSP-300 spectra; solid squares and circles, respectively). Error bars added to S mark the typical measurement uncertainty range of $30 \%$ representative for all distributions. For more details, see text.

Differences such as those between distributions AT and $\mathrm{S}$ are systematically found comparing jet exhaust distributions under contrail- and noncontrail-forming conditions and imply that the main mass content of the particles detected in excess of $\mathrm{S}$ is ice water.

Distributions A and B in Table 2 (A also shown in Fig. 1) represent two exemplary cases of nonpersistent contrails: A, a less than $3 \mathrm{~s}$ aged contrail of an Airbus A-310 jet aircraft measured close to the plume edge (actually in the upper mixing region); and B, a contrail of a Boeing B-757 approximately 20-30 s past formation. Contrail A, strongly subsaturated at $\mathrm{RH}=30 \%$, already vanished after approximately $1 \mathrm{n} \mathrm{mi} \mathrm{(plume} \mathrm{age}$ 5-8 s) flight distance, while B, measured at about RH $=40 \%$, evaporated more slowly.

The distributions to the right-hand side of AT in Fig. 1 illustrate growing contrails sampled close to or above ice-saturated conditions at altitudes between 9.5 and $11.5 \mathrm{~km}$. Such contrails have been found to be more stable in time and their mean crystal diameters reach larger values, up to about $8-10 \mu \mathrm{m}$. Case A1 (Fig. 1) belongs to an A-310 contrail of 70-s age, and case A2 (Fig. 1) shows an approximately 3-min-old A-300 contrail. Cases B1 and B2, respectively, represent one and the same B-737 contrail about 1-2 min and 10 min past generation, and case D a DC-9 contrail about 3 min past exit.

Older contrails structures are O (Fig. 1), an unidentified, at least 12-15 min old, and U (Figs. 1, 2), measured in a rare case of a contrail that was definitely older than $0.5 \mathrm{~h}$. The broadening of the spectra during the transition from, for example, AT to $\mathrm{O}$, could result from mixing processes inside an aging contrail that lead to superposition of crystal modes with different mean sizes formed due to spatial variations of humidity and temperature. The contrail crystal distribution U, with concentrations of $n=10-20 \mathrm{~cm}^{-3}$ and $D_{m}=9 \mu \mathrm{m}$, comes closest to that observed in a young cirrus (case $\mathrm{Cf}$ in Fig. 1 and section 3b) and illustrates the almost completed transition state between a contrail and a young cirrus cloud. Unfortunately, neither FSSP-300 and accurate RH measurements, nor information on the generating aircraft is available for case U. No ice crystals larger than about $25 \mu \mathrm{m}$ have been detected by the OAP2DC inside or in the vicinity of that particular cloud structure.

Contrails with progressively increasing age (from AT to U) obviously exhibit a continuous decrease of ice crystal concentrations caused by plume dispersion. At the same time, their mean diameters increase from ini- 


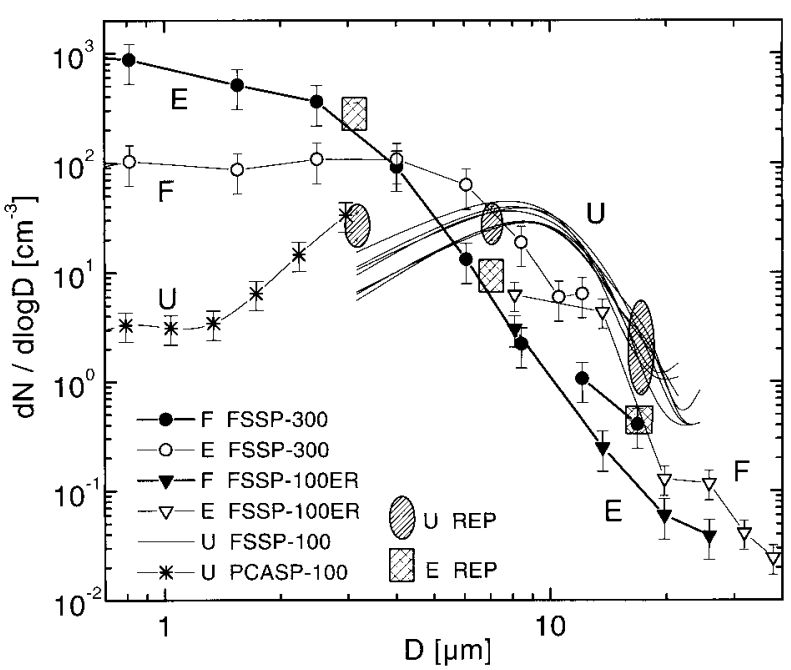

FIG. 2. Comparison of contrail ice crystal distributions derived from optical spectrometers (lines with small symbols and error bars) with replicator data (large symbols). Replicator data concern cases E and U, PCASP data (stars), and FSSP-100 data (line group) refer to case U only. Comparisons between FSSP-300 data (circles) and FSSP100ER data (triangles) concern the cases $\mathrm{E}$ (solid symbols) and F (open symbols) and overlap in the diameter range of 6-20 $\mu \mathrm{m}$. For interpretation, see text.

tially $1 \mu \mathrm{m}$ to about $10 \mu \mathrm{m}$ on the timescale of about $30 \mathrm{~min}$.

Figure 2 contains a comparison of spectral information retrieved from different instruments. Distributions $\mathrm{E}$ and $\mathrm{F}$ are an unidentified contrail about 5-8 min downwind of a highly frequented air corridor and a 1012-min aged contrail of the Falcon aircraft, respectively. They demonstrate the most common response characteristics of FSSP-300 and FSSP-100ER in the overlap region of their detection ranges between about 6 and 20 $\mu \mathrm{m}$ where sampling has been conducted in contrails. For cases $\mathrm{E}$ and $\mathrm{F}$ both instruments agree within a factor of about 2. We note that only in very fresh plumes with very high crystal concentrations do the FSSP-300 readings exceed those of the FSSP-100, possibly an effect of multiple particle coincidences. On the other hand, in cases of very short sampling periods ( $\ll 1 \mathrm{~s})$ the FSSP300 readings occasionally fall below those of the FSSP100 , most likely due to poorer sampling statistics (much smaller effective sampling volume) of the FSSP-300.

A direct comparison of FSSP/PCASP with REP data, applied to the cases $\mathrm{E}$ and $\mathrm{U}$, is also documented in Fig. 2. For these cases concentrations fit within a factor of 2 in the diameter range 5-30 $\mu \mathrm{m}$. (Other cases where $n_{\mathrm{FSSP} 100}$ would have strongly exceeded $n_{\mathrm{REP}}$ have not been observed.) Only the concentrations for particles smaller than about $5 \mu \mathrm{m}$ for case $\mathrm{U}$ significantly disagree, due to reduced sampling efficiency in the lowest FSSP-size channel (The FSSP-100ER has here been operated in the $2-47-\mu \mathrm{m}$ range.) The real spectrum of $U$ can be expected to resemble the combined trend of PCASP and REP data points comparable to the shape of case F (and also case O) toward smaller diameters, thus in agreement with all other observations including FSSP-300 information.

Figures $3 \mathrm{a}-\mathrm{c}$, containing replica images of the contrails E (Fig. 3b) and U (Fig. 3c), show that almost all ice crystals in fresh contrails (Fig. 3a) are formed quite regularly (close to spherical shape) and that this holds even for the major fraction of the crystals at contrail ages up to about $0.5 \mathrm{~h}$. Thus, the contrail crystal shapes correspond closely to the assumption upon which the FSSP-measurement analysis is based. This result, together with the agreement between FSSP and REP crystal concentrations, is usually found in contrails and yields a strong support for the reliability of both FSSPderived crystal concentrations and size distributions in contrails, at least for the observed cases with mean diameters below $D_{m}=15-20 \mu \mathrm{m}$.

In summary, growth of the observed contrails is characterized by an increase in mean diameter from $1 \mu \mathrm{m}$ to about $8 \mu \mathrm{m}\left(D_{\text {eff }}=1.5-10 \mu \mathrm{m}\right)$ on timescales up to about $1 \mathrm{~h}$. During that period the crystal concentrations decrease by almost three orders of magnitude from $>2000 \mathrm{~cm}^{-3}$ down to $10-15 \mathrm{~cm}^{-3}$ caused by plume dilution. The variability of observed concentrations and crystal spectra is high in the near field (which includes the jet and vortex phases up to about $2 \mathrm{~min}$ ). The ice crystal spectra exhibit typical variations roughly characterized by distributions A, AT, B1, and D on spatial scales of only several tenths of a meter $(<0.1 \mathrm{~s})$ in flight direction, some of them indicative of ice-saturated, isolated plume regions (like AT) and others representing the conditions close to the plume border (like A). Typical near-field contrails contain much more than 1000 $\mathrm{cm}^{-3}$ ice crystals. Less variability in the crystal spectra is observed after the near-field phase, where concentrations have decreased to several $100 \mathrm{~cm}^{-3}$ and the particles passed beyond diameters of $D_{m}=2 \mu \mathrm{m}\left(D_{\text {eff }}>\right.$ $3 \mu \mathrm{m})$. Here, the sampled regions were much more extended and homogeneous, permitting changes in the spectra to be related to the environmental conditions (see also section 4).

\section{b. Observations in cirrus}

In Fig. 4 we show cases of visible cirrus clouds in between 7.5- and 9.8-km (case C) and 10.5- and 10.8$\mathrm{km}$ altitude (case $\mathrm{Cf}$ ), at relative humidity around $60 \%-$ $65 \%(80 \%-85 \%)$ and temperatures of about $-50^{\circ} \mathrm{C}$ $\left(-60^{\circ} \mathrm{C}\right)$; see also Table 2 . Here $\mathrm{C}$ is represented by two distributions that characterize the typical variability range throughout dense cloud regions. In both cases two modes can be distinguished: one cloud mode around $D_{m}$ $=15-20 \mu \mathrm{m}(\mathrm{Cf}: 10 \mu \mathrm{m})$ and a second one toward submicron sizes to the left, which we call "haze mode." These two modes have been present in all cirrus cases observed with the FSSP-300 besides $\mathrm{C}$ and $\mathrm{Cf}$ and they are typically separated by a local minimum where the crystal concentrations decrease more than a factor of 

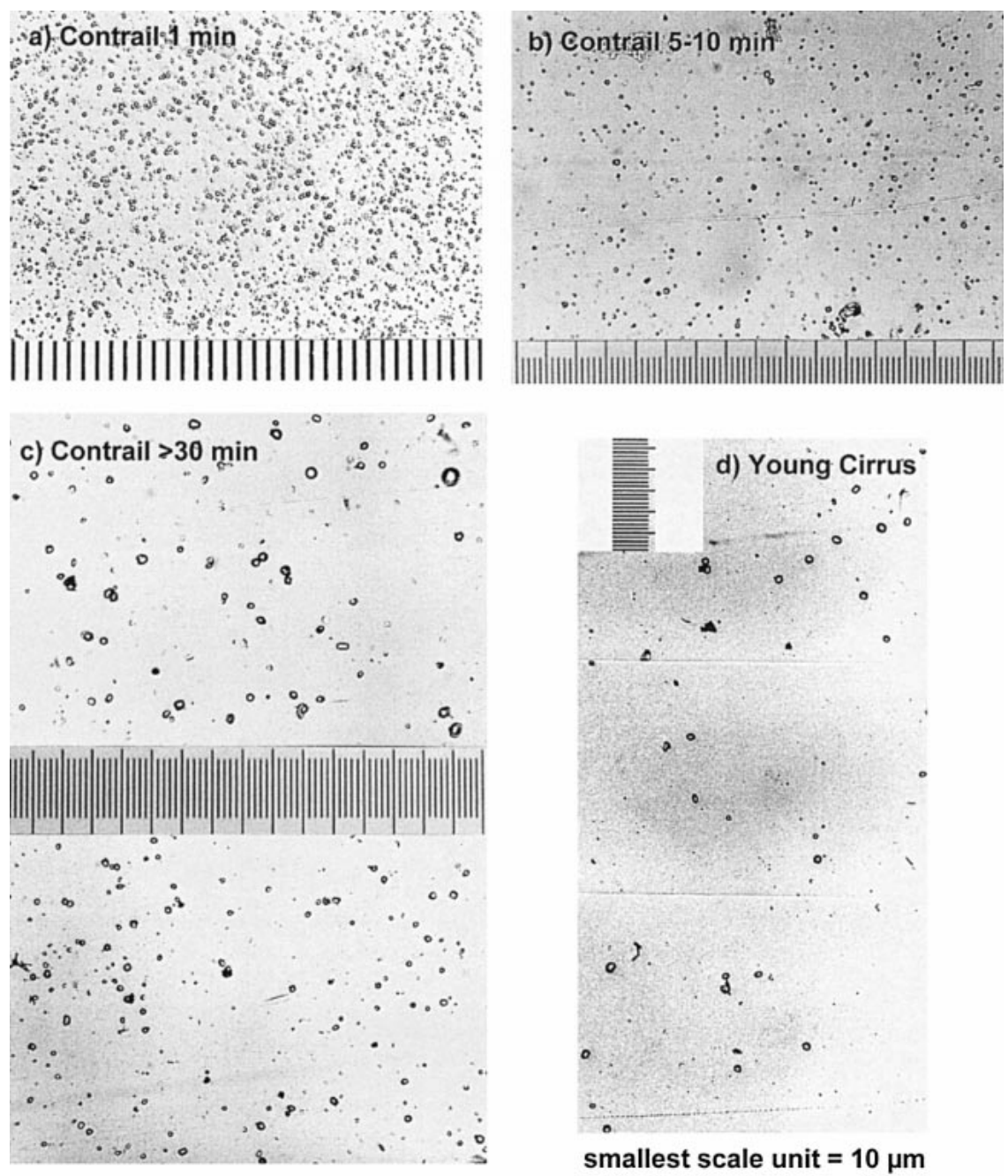

FIG. 3. Replica of contrail and young cirrus ice crystals: (a) contrail aged 1 min, (b) contrail aged 5-10 min (case E), (c) contrail older than 30 min (case U), and (d) developing cirrus (case Cf). The smallest scale unit is equal to $10 \mu \mathrm{m}$ for all cases.

10. In reality, the haze mode and the cloud mode can be expected to be even more distinct than indicated in Fig. 4, since the technical limitations of FSSP instruments generally imply a spectral spreading (e.g., Baumgardner et al. 1992) that will to some extent "fill up" a concentration gap within two local maxima. The haze mode likely consists of aerosol particles that have been hydrated but not activated as cloud condensation nuclei. The number concentrations of the haze mode show values of 5-8 $\mathrm{cm}^{-3}$ (Cf: $3-4 \mathrm{~cm}^{-3}$ ), consistent with aerosol distributions commonly present in the atmospheric accumulation mode size range. The actual upper-tropospheric background distribution measured in the cloudfree vicinity of $\mathrm{C}$ and $\mathrm{Cf}$ (Fig. 4) additionally illustrates that parts of the dry aerosol spectrum would have to experience hygroscopic growth by about a factor of 3 in diameter to appear as the haze mode of $\mathrm{C}$ or Cf. Hygroscopic growth as indicated by horizontal arrows in Fig. 4 is quite reasonable since in case $\mathrm{Cf}$ the $\mathrm{RH}$ is
$80 \%-85 \%$, above the deliquescence point for many known atmospheric aerosol types. This also holds for the cirrus $\mathrm{C}$ insofar as we know that this cirrus is more developed (meaning that $\mathrm{C}$ must have experienced higher RH in its early stage) and that a hydrated aerosol does not instantaneously fall back to its dry size when RH drops back below the deliquescence point (hysteresis effect; Pruppacher and Klett 1978). Further evaluated PCASP data that correspond to the old contrail case (U) additionally support that the haze modes of $\mathrm{C}$ and $\mathrm{Cf}$ contain hydrated aerosol. In the submicron diameter range - such aerosols are effectively dried out inside the instrument-the PCASP concentrations fall to the indicated tropospheric background values.

The number concentrations of the cloud mode ice crystals remain at values of $1-2 \mathrm{~cm}^{-3}$ (Cf: $3-5 \mathrm{~cm}^{-3}$ ). For case $\mathrm{C}$ the presence of larger ice crystals up to about $300-400 \mu \mathrm{m}$ in diameter (Fig. 4; OAP and REP) and a humidity close to ice saturation indicate an advanced 


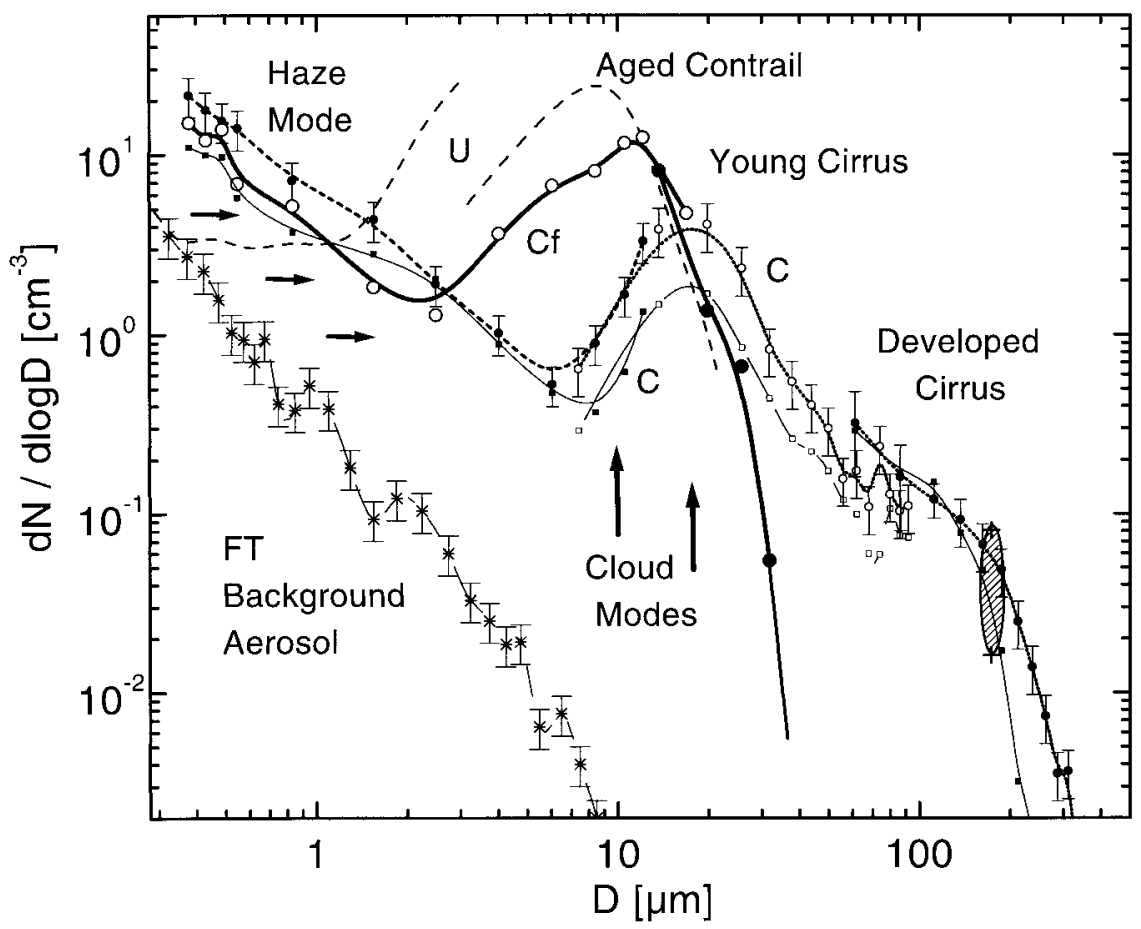

FIG. 4. Comparison of the size spectra of an aged contrail (U, no symbols, dashed lines; derived from FSSP-100 and PCASP), a young cirrus (Cf), a developed cirrus cloud (C), and an atmospheric background aerosol distribution (FT). Case Cf: large circles, bold line, open symbols for FSSP300, solid symbols for FSSP-100ER; case C: two distributions (small open symbols for FSSP-100 data, small solid symbols for FSSP-300 and OAP data) representing an approximate range of variability inside dense regions of the developed cirrus; case FT: star symbols, represents the actual free tropospheric background aerosol (averaged over several $\mathrm{min}$ ) in the wider vicinity of $\mathrm{C}$ and Cf. Representative $30 \%$ error bars are added to one distribution of $\mathrm{C}$ and to FT. A comparison with REP-derived crystal concentration $(>80-100 \mu \mathrm{m}$ diameter) is given by the large ellipsoid. Potential hygroscopic growth of background aerosols toward the coarse mode is indicated by short horizontal arrows. The mean mode diameter position of $\mathrm{Cf}$ and $\mathrm{C}$ is shown by upward-pointing arrows. For further interpretation, see text.

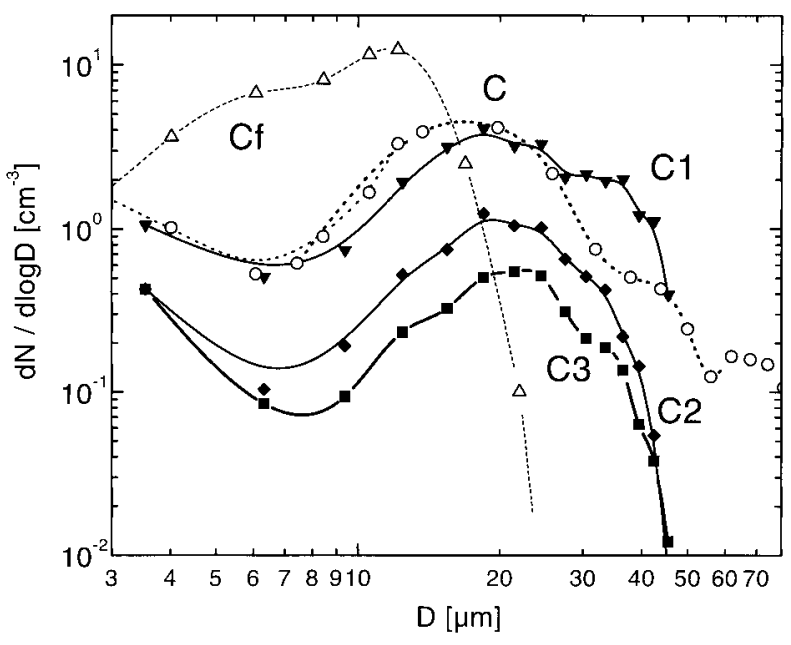

FIG. 5. Variability of the cloud mode sampled in cirrus clouds at different altitudes and temperatures on 14 Oct 1996. Case C1 (solid triangles): $T=-57^{\circ} \mathrm{C}, z=9.9 \mathrm{~km}$; case $\mathrm{C} 2$ (solid diamonds): $T=$ $-50^{\circ} \mathrm{C}, z=10.1 \mathrm{~km}$; case $\mathrm{C} 3$ (solid squares): $T=-62^{\circ} \mathrm{C}, z=10.6$ $\mathrm{km}$. Cases $\mathrm{C}$ (open circles, dotted) and $\mathrm{Cf}$ (open triangles, dashed line); see also Fig. 4. stage in the cloud's life cycle. Within the diameter range 50-100 $\mu \mathrm{m}$ we also observe good agreement (within a factor of 2) between FSSP-100 and OAP. According to Gayet et al. (1996), such agreement in the spectral overlap region of the instruments represents a criterion for the reliability of FSSP information obtained in the ice cloud.

With the help of Fig. 5, we discuss the variability of developed cirrus clouds sampled in the tropopause region between about 9.9- and 10.6-km altitude (C1-C3). The crystal concentrations vary between 0.3 and $3 \mathrm{~cm}^{-3}$, while the cirrus cloud mode is typically centered around $20 \mu \mathrm{m}\left(D_{\text {eff }}=25 \mu \mathrm{m}\right)$. Specific crystal surface area and ice water content from Table 2 (here exclusively derived from FSSP data) decrease with altitude. Note that the steep decline of $\mathrm{C} 1-\mathrm{C} 3$ toward $50-\mu \mathrm{m}$ diameter can possibly be attributed to a lowered sampling efficiency close to the FSSP range border $(47 \mu \mathrm{m})$ so that the real distributions more likely lie closer the shape of case C. This is also confirmed by the corresponding OAP information (not plotted). In case Cf almost no irregularly formed crystal shapes have been observed. Their quasi- 


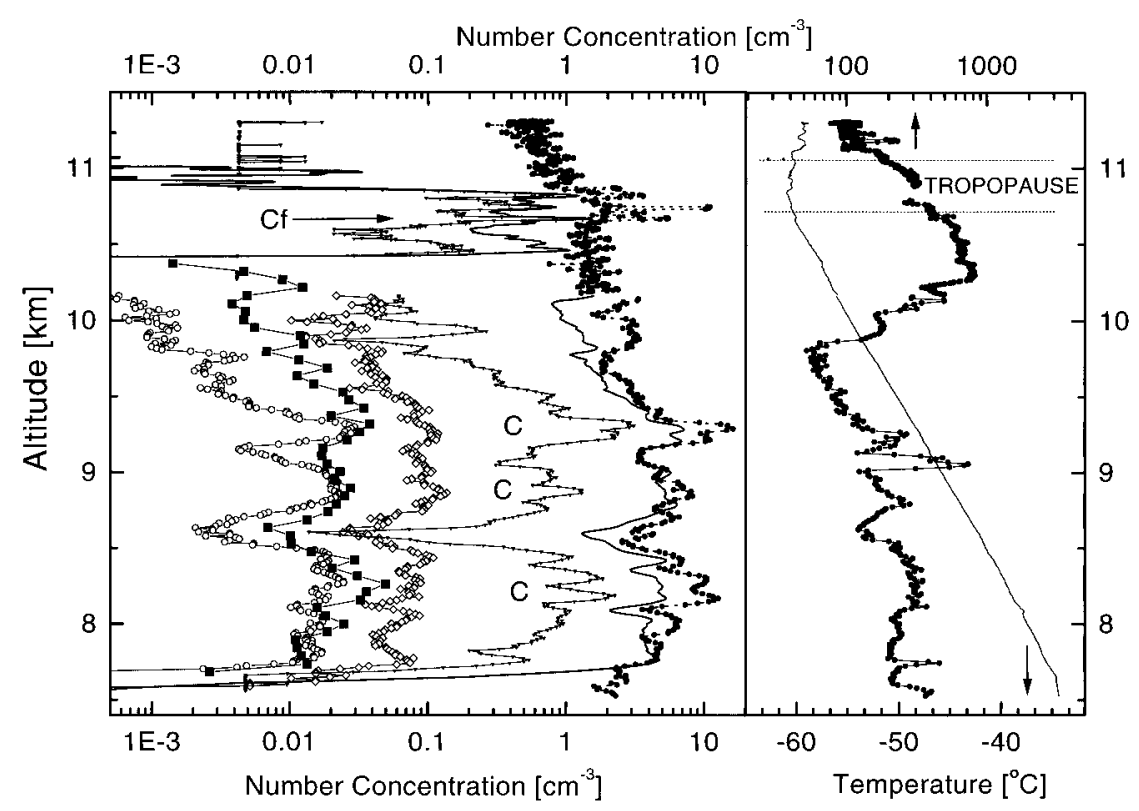

FIG. 6. Vertical profile of cirrus ice crystal and background aerosol concentrations, containing cases $\mathrm{C}$ and $\mathrm{Cf}$, measured on $25 \mathrm{Apr}$ 1996. From left to right: OAP $>100 \mu \mathrm{m}$ (open circles), REP $>80 \mu \mathrm{m}$ (solid squares), OAP $>20 \mu \mathrm{m}$ (open diamonds), FSSP-100ER $>6-8 \mu \mathrm{m}$ (solid triangles), CVI $>5 \mu \mathrm{m}$ (bold line), FSSP-300 $>0.4 \mu \mathrm{m}$ (bold points), and CN $\geq 0.01 \mu \mathrm{m}$ (right-hand panel). FSSP- and OAP-derived profiles are smoothed by a moving average over several seconds. The tropopause is located at about $11 \mathrm{~km}$ (see temperature profile, right-hand panel, thin line).

spherical, amorphous shape is documented by the REP images in Fig. 3d. In contrast to the developed cirrus (C, C1-C3) no crystals larger than about $30 \mu \mathrm{m}$ have been detected in case $\mathrm{Cf}$. Since $\mathrm{Cf}$ was further located within a few-hundred-meters-thick layer with a $0.25 \mathrm{~m}$ $\mathrm{s}^{-1}$ average updraft and high relative humidity $(>80 \%)$, it was most probably in a developing stage, justifying our assumption that $\mathrm{Cf}$ indeed represents a young cirrus cloud. Further, concentrations and shape of the distribution $\mathrm{Cf}$ agree with a detailed model study of cirrus cloud formation by Lin et al. (1998).

Figure 6 illustrates in more detail the vertical distribution of ice crystal and aerosol particle concentrations related to $\mathrm{C}$ and $\mathrm{Cf}$. Note the agreement between information derived from different optical and nonoptical detection methods: the vertical concentration trends and variability are mostly reflected similarly by the different instruments. We find REP cumulative concentrations of large crystals $(>80-100 \mu \mathrm{m})$ lying between OAP concentrations derived from readings $\geq$ channel 2 and $\geq$ channel 4 ( $>40 \mu \mathrm{m}$ and $>100 \mu \mathrm{m}$, respectively), as well as $n_{\mathrm{CVI}}$ between $n_{\mathrm{FSSP} 100}$ and $n_{\mathrm{FSSP} 300}$. For case C and with respect to the crystal breakup artifacts of the REP, $n_{\mathrm{CVI}}$ has been used to compare cirrus ice crystal concentrations between about 5 and $80 \mu \mathrm{m}$ with the FSSP100 -derived concentrations. Here $n_{\mathrm{CVI}}$ mostly exceeds $n_{\text {FSSP100 }}$ by a factor of $1.5-3$ (Fig. 6). Regarding the FSSP-100ER lower size detection limit of 6-8 $\mu \mathrm{m}$ (which is close to the limit of $5 \mu \mathrm{m}$ for the CVI), one would expect more comparable concentrations indicated by both instruments. The assumption of one residue particle per ice crystal for the CVI becomes problematic and perhaps aerosol scavenging on cirrus crystals as well as crystal breakup effects inside the probe can lead to higher-than-real concentrations indicated. We admit that the CVI probe used in these experiments contains a second virtual impactor internally, which reduces some of the potential sampling problems (see Ström and Heintzenberg 1994; Ström et al. 1994), while limiting the upper detection limit. However, expecting (e.g., Platt and Spinhirne 1989) that the FSSP-100, in the presence of many large crystals, indicates more than an order of magnitude higher than real crystal concentrations would then lead to higher concentrations compared to the CVI, which is obviously not the case and thus serves as an argument for the reliability of the FSSP-100 data.

Note also the strong aerosol loading below and throughout the tropopause around $10.5-\mathrm{km}$ altitude, which represents a distinct difference of the environmental conditions in which the cold cirrus $\mathrm{Cf}$ compared to case $C$ have been formed (100-200 $\mathrm{cm}^{-3}$ for $C, 500$ $\mathrm{cm}^{-3}$ for $\left.\mathrm{Cf}\right)$. Such high abundance of fine aerosol particles $\left(1000 \mathrm{~cm}^{-3}\right)$ in the tropopause region is often observed in the Northern Hemisphere midlatitudes. This region is frequently affected by air traffic particle emissions (Schumann 1997; Mannstein et al. 1999), a yet poorly quantified anthropogenic source of aerosols. We wonder whether or not the Cf particle spectrum (con- 
taining more and smaller crystals compared to C) could in any form be linked to the higher $\mathrm{CN}$ concentrations in the atmospheric background. In fact, one single model study of Lin et al. (1998) predicts a doubling of resulting cirrus crystal concentrations and a decrease in effective crystal diameter if the initial aerosol number concentration is increased from 150 to $500 \mathrm{~cm}^{-3}$. However, this study is alone among several others (e.g., Heymsfield and Sabin 1989; Jensen and Toon 1997; DeMott et al. 1994) that claim that at least an order of magnitude higher aerosol concentrations is needed to cause a doubling of crystal concentrations for comparable scenarios. Regardless to which extent the strong tropopause loading with Aitken-mode aerosol (as shown in Fig. 6) is of natural or anthropogenic origin, the consideration of an aerosol-to-cloud linkage appears to be a decisive issue in understanding the life cycles of ice clouds.

The presented observations may also support the idea that homogenous freezing of solution droplets is an important process of cirrus cloud generation in the upper troposphere (as, e.g., suggested by Heymsfield and Sabin 1989; Heymsfield and Miloshevich 1993). A few haze droplets per cubic centimeter have been detected in all cirrus clouds sampled by the FSSP-300. Such micron-sized particles can be regarded as favorable sites for water vapor deposition compared to less abundant ice nuclei, and thus are potential candidates for the transformation into the quasi-spherical ice crystals of 10-15 $\mu \mathrm{m}$ that have been imaged by the replicator in the young cirrus Cf (Fig. 3d).

\section{c. Comparison of contrails and cirrus}

Figure 7 shows a selection of surface area distributions corresponding to the cases listed in Table 2. The persistent near-field distributions AT, B1, and D clearly exceed specific surface area values of $10^{4} \mu \mathrm{m}^{2} \mathrm{~cm}^{-3}$ and effective diameters of $2 \mu \mathrm{m}$, whereas the evaporating contrails A and B stay below $4000 \mu \mathrm{m}^{2} \mathrm{~cm}^{-3}$ and $D_{\text {eff }}=1.5 \mu \mathrm{m}$. In contrails in the dispersion regime (E, $\mathrm{A} 2, \mathrm{~B} 2, \mathrm{O}$, and $\mathrm{U}$ ), the surface area density decreases to typically $3500 \mu \mathrm{m}^{2} \mathrm{~cm}^{-3}$ and does not change significantly thereafter. From this stage on crystal growth by deposition of ambient water vapor in persistent contrails tends to compensate ongoing plume dilution indicated by the shift of the surface distributions toward larger diameters along E, A2, B2, O, and U. Cirrus clouds like $\mathrm{Cf}$ and $\mathrm{C}$ extend the trend toward larger crystal diameters, characterized by surface area densities of about 3100 and $>3500 \mu \mathrm{m}^{2} \mathrm{~cm}^{-3}$, respectively, values comparable to those of the persistent contrails. As soon as the contrail has reached a few minutes of age, the specific surface area apparently represents an almost invariant property with no significant trend along the growth from $D_{m}=1.5 \mu \mathrm{m}$ to about $15 \mu \mathrm{m}$. At least the displayed cases of the dispersion regime contrails (including the young cirrus $\mathrm{Cf}$ ) do not vary within more than a factor of 2 (Table 2). Considering this variability

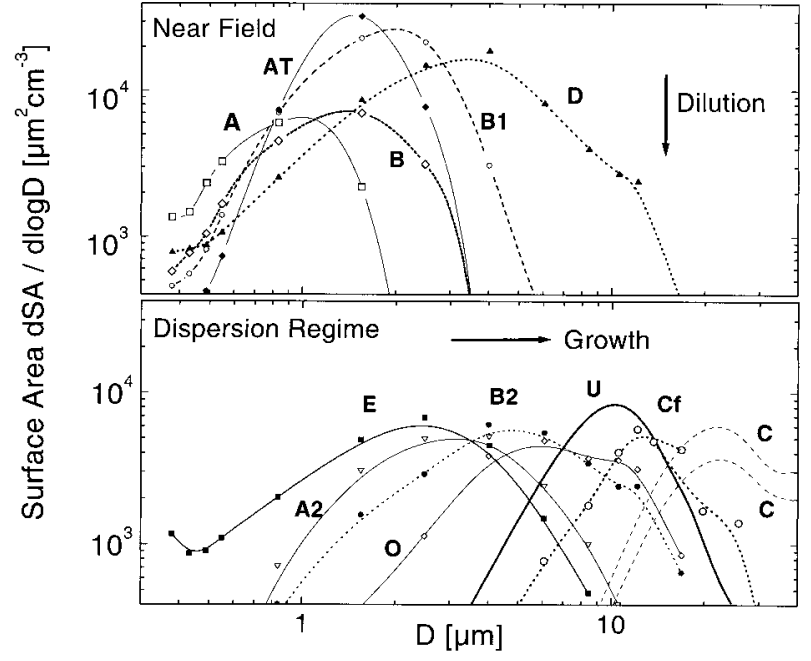

FIG. 7. Evolution of ice crystal surface area distributions inside aging contrails. (upper) Near-field distributions, showing the effect of plume dilution on the spectra: A (open squares, solid line), B (open diamonds, dotted), AT (solid diamonds, solid line), B1 (open circles, dashed), D (solid triangles, dotted). (lower) Dispersion regime contrails and cirrus clouds, showing crystal growth during the transformation of contrail into young cirrus clouds: E (solid squares, solid line), A2 (open triangles, solid line), B2 (solid circles, dotted), O (open diamonds, solid line), U (no symbols, bold line), Cf (open circles, dotted), C (no symbols, dashed line).

in observations together with about $30 \%$ measurement uncertainty for optically derived crystal number densities suggests a range of about $\mathrm{SA}=3500 \mu \mathrm{m}^{2} \mathrm{~cm}^{-3}$ $\pm 40 \%$ as characteristic value for persistent contrails on timescales of a few minutes up to an hour. Since the extinction efficiency $Q_{\text {ext }}$ for water droplets (here calculated for $0.5-\mu \mathrm{m}$ wavelength) does not vary more than $2.3 \pm 25 \%$ (Seinfeld and Pandis 1997) within the considered diameter range $(1.5-15 \mu \mathrm{m}), Q_{\text {ext }}$ is nearly constant (with respect to already $\pm 40 \%$ uncertainty in SA). Hence, the optical extinction coefficient (at $0.5-\mu \mathrm{m}$ wavelength) of the discussed contrails in the dispersion regime can be regarded as a quantity proportional to the specific particle cross section within a $\pm 50 \%$ uncertainty range. Considering this limitation the measurement results shown in Fig. 7 demonstrate that the specific optical extinction coefficient (per unit length) of persistent contrails can be expected to be comparable to that of a typical (young) cirrus, variable within about a factor of 3. However, whereas aged contrails and young cirrus exhibit similarities in terms of their microphysical properties, most contrails are confined to relatively thin layers compared to many cirrus clouds.

Finally, two examples (A3 and B3) shown in Fig. 8 demonstrate the coexistence of contrails and cirrus clouds as measured by the FSSP-100ER limited to the 2-47- $\mu \mathrm{m}$ diameter range (not included in Table 2). Two distributions for each case have been achieved by sampling 10-20 s inside as well as in the vicinity of the contrails that were embedded into visible cirrus. Case 


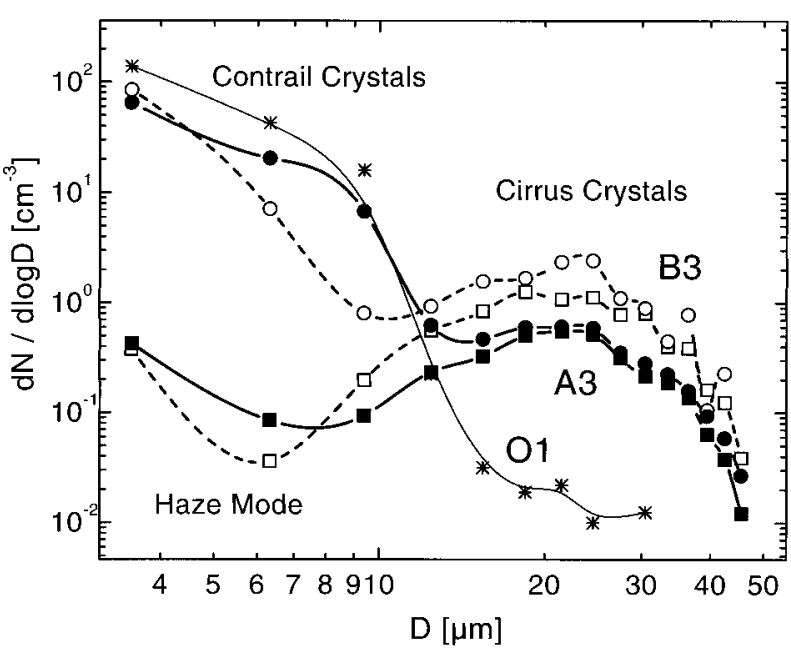

FIG. 8. Comparison of ice particle distributions measured inside cirrus clouds with (circles) and without (squares) embedded contrail structures. Cases B3 (dashed lines) and A3 (bold lines) represen distributions sampled in upper-tropospheric cirrus clouds; case $\mathrm{O} 1$ (stars, solid line) represents a few-minutes-aged contrail outside cirrus under comparable conditions. These cases are limited to FSSP-100 (2-47- $\mu \mathrm{m}$ range) data and thus are not documented in Table 2.

A3 represents a 1.5 -min-aged A-320 contrail $(T=$ $\left.-56^{\circ} \mathrm{C}, z=10.9 \mathrm{~km}\right)$ and B3 a 2.5 -min-old B-737 contrail $\left(T=-52^{\circ} \mathrm{C}, z=10.2 \mathrm{~km}\right)$. Although these cases are limited to FSSP-100 observations $(2 \mu \mathrm{m}<D<50$ $\mu \mathrm{m})$ they demonstrate how embedded contrails dominate the crystal concentrations below $D_{m}=10 \mu \mathrm{m}$. Between 2 and $10 \mu \mathrm{m}$, about two orders of magnitude higher crystal concentrations are found in the embedded contrails compared to the haze mode of the pure cirrus clouds. On the other hand, the distributions corresponding to embedded contrails and pure cirrus do not deviate significantly from each other in the diameter range above $10 \mu \mathrm{m}$, proving that those crystals almost completely originate from the surrounding ice cloud. Further, the distribution $\mathrm{O} 1$, a somewhat more aged (unidentified) contrail measured under similar conditions as A3 and B3, but in the absence of a visible cirrus, principally resembles $\mathrm{A} 3$ and $\mathrm{B} 3$ in the range below 10 $\mu \mathrm{m}$. The fact that the smaller crystals in case $\mathrm{O} 1$ have not grown to significantly larger diameters compared to A3 and B3 seems to indicate that contrail growth is not necessarily quenched by the presence of a cirrus cloud. This suggestion will be addressed, among other topics, in the following model section.

\section{Contrail transition into cirrus}

The questions of how fast contrails transform into cirrus-type clouds and which are the most important atmospheric conditions that control this contrail-cirrus transformation are of central importance in studies aiming at an assessment of the chemical and radiative impact of contrails. In the following, we present some estimates based on a simple parcel model to work out the general features of contrail evolution. The results are compared with the observations discussed above and allow further conclusions.

\section{a. Model description}

Contrails require air that is supersaturated with respect to ice [relative humidity over ice $(\mathrm{RHI})>100 \%$ ] in order to be persistent (e.g., Gierens 1996; Jensen et al. 1998). When the contrail forms in an aircraft plume at plume ages $0.1-0.3 \mathrm{~s}$ after emission of the exhaust, the aircraft wake is ice saturated and typically contains several $10^{4}$ ice particles per cubic centimeter with mean diameters around $1 \mu \mathrm{m}$ or below (Kärcher et al. 1996). In this initial contrail growth stage, the water vapor emitted by the aircraft engines condensed onto the ice particles. They can continue growth by further deposition of $\mathrm{H}_{2} \mathrm{O}$ that is entrained into the wake from icesupersaturated background air by mixing processes. The mixing processes cause dilution of both ice particles and $\mathrm{H}_{2} \mathrm{O}$ vapor in the contrail. We use the following approximate equations for the evolution of the $\mathrm{H}_{2} \mathrm{O}$ volume mixing ratio $x_{w}, \mathrm{H}_{2} \mathrm{O}$ mass per contrail crystal (represented by one single size) $m$, crystal volume mixing ratio $x_{w}$, and temperature $T$, inside the contrail as a function of the time after contrail formation $t$ :

$$
\begin{aligned}
d x_{w} / d t & =-j_{w} x-\left(x_{w}-x_{w a}\right) \alpha / t \\
d m / d t & =m_{w} j_{w} \\
x(t) & =x_{0}\left(t_{0} / t\right)^{\alpha} \\
T(t) & =T_{a}+v(d T / d t)_{\mathrm{ad}}\left(t-t_{0}\right) .
\end{aligned}
$$

Number densities $(n)$ and volume mixing ratios $(x)$ are linked by the ideal gas law to compute the air density $M$ (at the pressure $p=250 \mathrm{hPa}$ ) and calculate $x=n / M$. In (1) and (2) $j_{w}$ denotes the flux (per unit time) of $\mathrm{H}_{2} \mathrm{O}$ molecules from the gas phase toward the small ice particles as defined by Kärcher et al. (1996), taking into account the transition between the free molecular and diffusion-limited regimes. This flux is driven by the relative humidity in the contrail, given as RHI $=100 \%$ $\times n_{w} / n_{\text {sat }}$, where $n_{\text {sat }}$ is the $\mathrm{H}_{2} \mathrm{O}$ equilibrium number density over ice. An $\mathrm{H}_{2} \mathrm{O}$ deposition coefficient on ice of 0.5 is used in the calculations. Ventilation and latent heat corrections of the flux, crystal coagulation, and breakup processes, and sedimentation losses are unimportant due to the relatively small contrail crystal sizes below about $10 \mu \mathrm{m}$ and at the cold temperatures and short timescales considered here. Radiative effects on the growth of young contrails are expected to be small (Gierens 1996) and are not considered. In (1) $x_{w a}$ is the ambient (subscript $a$ ) $\mathrm{H}_{2} \mathrm{O}$ mixing ratio entrained into the plume, and $\alpha$ is a constant mixing parameter. In (2) $m_{w}$ denotes the mass of one $\mathrm{H}_{2} \mathrm{O}$ molecule. The volume mixing ratio $x(t)$ of the monodisperse ice crystals follows from the dilution law (3a) starting with an 
initial concentration $x_{0}=x\left(t_{0}\right)$, and (3b) gives $T(t)$ when a constant updraft velocity $v$ is prescribed, assuming an adiabatic lapse rate of $(d T / d z)_{\text {ad }}=0.01 \mathrm{~K} \mathrm{~m}^{-1}$. The initial values $T\left(t_{0}\right)=T_{a}, v, x_{0}$, and $x_{w a}$ are free parameters.

Both (1) and (2) are integrated numerically starting at $t_{0}=10 \mathrm{~s}$ at ice saturation in the plume. To simulate a typical dilution and mixing history of a contrail, we use $\alpha=0.9$. The first 2-3 min are characterized by reduced dilution rates (Gerz et al. 1998), which we model using $\alpha / 10$ in the interval $t_{0}<t<2 \mathrm{~min}$. This approach is in fair agreement with dilution rates inferred from in situ measurements compiled by Schumann et al. (1998) and with lidar observations of the horizontal spread of contrails by Freudenthaler et al. (1995). Later we will vary $\alpha$ to estimate the sensitivity of the average contrail crystal diameter $D$ (initial value $D_{0}=1 \mu \mathrm{m}$ ) to account for a possible variability of the contrail dilution. The size $D$ is evaluated from the particle mass $m$ assuming spherical particles. As seen in the REP data in Fig. 3, this is a good approximation during the contrail-cirrus transformation period (i.e., during the first hour after contrail formation). The updraft velocity is kept constant as the parcel is lifted by $500 \mathrm{~m}$ and afterward set to zero. Lifting by this distance corresponds to an adiabatic cooling of $5 \mathrm{~K}$, while the relative humidity can be increased from ice to approximately water saturation under upper-tropospheric conditions. Finally, we compute the number density of entrained $\mathrm{H}_{2} \mathrm{O}$ vapor from $n_{w a}=\left(\mathrm{RHI}_{a} / 100 \%\right) n_{\text {sat }}\left(T_{a}\right)$ and assume that it stays constant over the simulation period. Thus, the air parcel including the contrail particles is lifted in a background with constant absolute humidity. At the same time, we do not allow additional crystals to nucleate, although the humidity may acquire values sufficient to induce ice nucleation. Of course, these assumptions only allow a highly simplified description of the development of persistent contrails, but the general conclusions drawn will not be changed by including such details.

\section{b. Model results and discussion}

We discuss solutions of Eqs. (1)-(3), varying the model parameters within ranges that we believe are typical for persistent contrails under upper-tropospheric conditions, that is, $v=0-0.4 \mathrm{~m} \mathrm{~s}^{-1}, n_{0}=1000-5000$ $\mathrm{cm}^{-3}$, and $\mathrm{RHI}_{a}=100 \%-150 \%$. The initial ice number density $n_{0}$ in this range is consistent with a visibility analysis of new contrails (Kärcher et al. 1996) and in situ observations (Petzold et al. 1997). Variability of $n_{0}$, which may even be smaller than $1000 \mathrm{~cm}^{-3}$, is mainly introduced by the fact that we do not know a priori which portion of the near-field plume (characterized by a pronounced spatial variability in terms of particle concentrations) grows in the atmosphere, and to a lesser content, due to uncertainties in aerosol growth processes leading to ice nucleation in the nascent plume (Kärcher et al. 1998). The prescribed range of RHI comprises ice humidity values observed in the upper troposphere. It is important to note that regions with up to $\mathrm{RHI}=150 \%$ devoid of cirrus clouds have frequently been observed (Heymsfield et al. 1998b).

Figure 9 depicts the mean contrail crystal diameter $D$ after $1 \mathrm{~h}$ of growth as a function of RHI (Fig. 9a), $v$ (Fig. 9b), and $n_{0}$ (Fig. 9c) in an atmosphere with an initial temperature $223 \mathrm{~K}$ (solid lines), $213 \mathrm{~K}$ (dashed lines), and $233 \mathrm{~K}$ (dotted-dashed lines). The modelderived size $D$ should be compared with the mean diameters inferred from our observations as compiled in Table 2. From the above discussion of contrail evolution, $t=1 \mathrm{~h}$ is a representative time span after which we expect that the microphysical properties of persistent contrails approach those of young cirrus clouds (cf. Figs. 1 and 4). We remark that variations of the mixing rate $\alpha$ within values $0.8-1$ translate into changes of $D$ of the order $\pm 0.5 \mu \mathrm{m}$ (at $213 \mathrm{~K}$ ) to $\pm 1 \mu \mathrm{m}$ (at $233 \mathrm{~K}$ ), whereby faster contrail dilution leads to lower relative humidity and smaller particle growth rates.

Figure 9a shows that $D$ increases with increasing humidity and with increasing temperature. A higher relative humidity serves to increase the available $\mathrm{H}_{2} \mathrm{O}$ vapor $n_{w}$ and a warmer temperature increases the crystal growth rate at fixed RHI. Placing the contrail in a moderate updraft $\left(0.25 \mathrm{~m} \mathrm{~s}^{-1}\right)$ and using a value $2500 \mathrm{~cm}^{-3}$ for the initial contrail ice particle number density at 10 s, this leads to $D=7-9 \mu \mathrm{m}$ at $223 \mathrm{~K}$. The increase in $n_{\text {sat }}$ with increasing $T$ enhances the growth rates (and causes $D$ values to increase with $T$ ) in all cases discussed below.

Figure $9 \mathrm{~b}$ depicts the crystal diameter at fixed values RHI and $n_{0}$ as a function of the updraft velocity. Clearly, increasing $v$ leads to larger crystals because higher cooling rates are reached in the air parcels when $v$ rises. (Note that the total cooling is limited to $5 \mathrm{~K}$ in each case, but $T$ decreases faster when $v$ is higher.) This effect saturates for $v>0.2 \mathrm{~m} \mathrm{~s}^{-1}$ because cooling for larger updraft velocities is nearly instantaneous with respect to the crystal growth timescales at the prescribed temperatures.

Finally, Fig. 9c displays the sensitivity of $D$ on the assumed number of initial contrail ice particles. Clearly, $D$ decreases when $n_{0}$ rises because at fixed values RHI and $v$ the same amount of available $\mathrm{H}_{2} \mathrm{O}$ is distributed among more particles, decreasing their average size. The changed scale for $D$ indicates that $n_{0}$ is the most sensitive parameter for contrail growth within the given parameter space.

\section{c. Contrail growth in the presence of preexisting cirrus clouds}

The evolution of the average size of crystals in growing contrails depicted in Fig. 9 is largely consistent with the observations discussed in Figs. 1 and 7. The model roughly confirms both the high concentrations of small ice crystals between 2 and $10 \mu \mathrm{m}$, as well as typical 

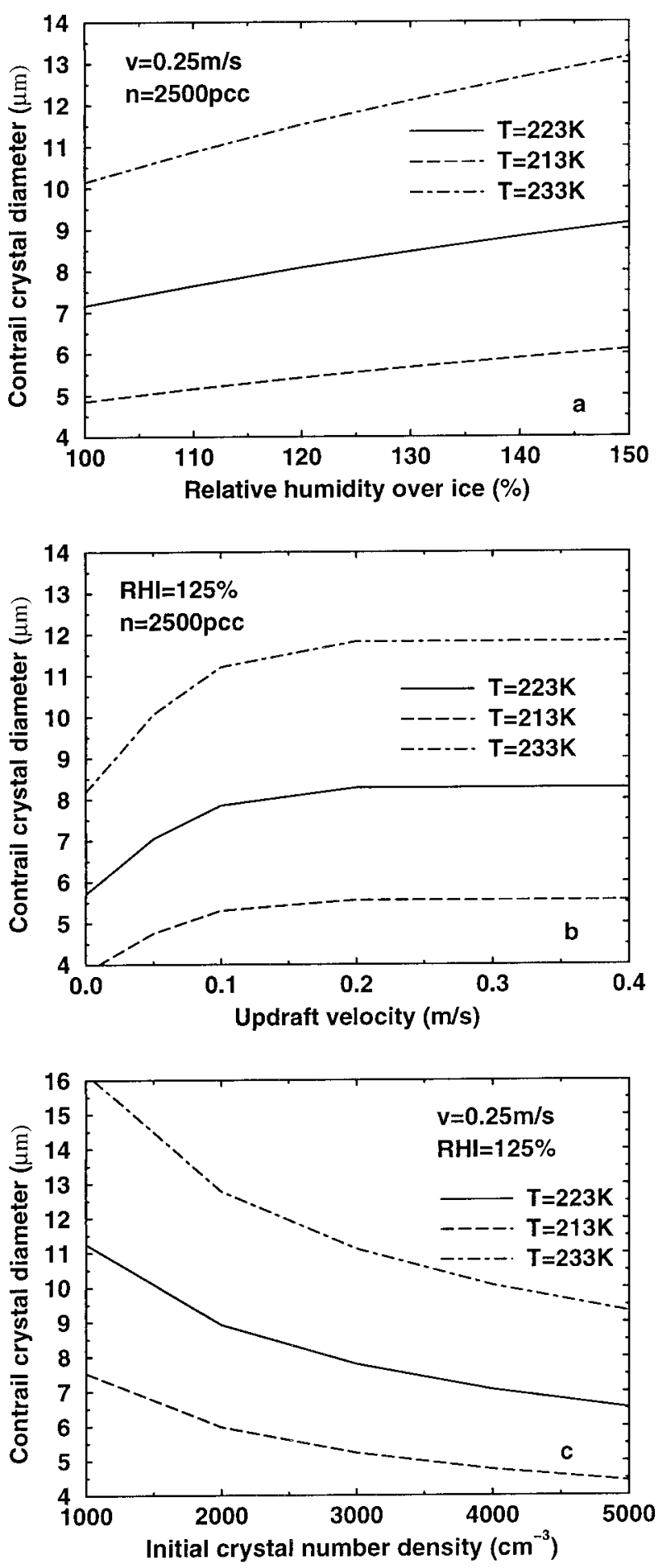

FIG. 9. Results from the simplified parcel model equations (1)-(3) for the microphysical evolution of a contrail at $250 \mathrm{hPa}$. The average contrail crystal diameter at $1 \mathrm{~h}$ after contrail formation is shown as a function of (a) relative humidity over ice RHI, (b) updraft velocity $v$, and (c) initial ice crystal number density $n_{0}$. Solid, dashed, and dotted-dashed lines are for an initial temperature of 223, 213, and $233 \mathrm{~K}$, respectively. The legends indicate which parameters are kept constant in each case. In the simulation, the updraft lasted until the parcel was lifted by $500 \mathrm{~m}$, corresponding to a temperature decrease of $5 \mathrm{~K}$. The ice crystals and water vapor are diluted in the contrail growth times of about $0.5-1 \mathrm{~h}$. Observations and model results only describe properties of the contrail core. Crystals located at the contrail edges, which are less abundant, may experience higher supersaturations over longer timescales, and thus grow larger and undergo gravitational settling. If the temperature gradient is sufficiently steep in the atmosphere and ice supersaturation can be maintained, growth of these larger crystals will be further enhanced, because temperature and depositional growth rates increase during sedimentation, producing the fall streaks that are occasionally observed (Knollenberg 1970).

It is further interesting to estimate the effects of preexisting cirrus crystals on the growth of contrail ice particles. This will in general require the use of a comprehensive cloud physics model, but a simple estimate can be given by inspecting the mass growth rate $j_{w}$ that enters Eqs. (1) and (2). If cirrus particles compete with contrail particles for the available $\mathrm{H}_{2} \mathrm{O}$, the $\mathrm{H}_{2} \mathrm{O}$ reservoir will be depleted according to (neglecting entrainment processes)

$$
d n_{w} / d t=-j_{w} n(t)-j_{w c} n_{c},
$$

where $j_{w c}$ and $n_{c}$ denote the $\mathrm{H}_{2} \mathrm{O}$ flux to the cirrus crystals and the cirrus particle number density (both assumed constant), respectively. Keeping the spherical approximation for the growth law and the above-mentioned assumptions, the cirrus particles will preferentially grow as soon as the second term on the right side of Eq. (4a) exceeds the first term. At fixed values $\mathrm{RHI}_{a}$ and $T_{a}$ and defining the mean cirrus crystal diameter as $D_{c}$, the relationship

$$
R=D_{c} n_{c} /(D n)>1
$$

yields the requirement for the cirrus particles to grow faster (and hence dominate the loss of $\mathrm{H}_{2} \mathrm{O}$ vapor) than the ice particles in the contrail. In Fig. 10 we plot the time evolution of the product $D n$ at a constant temperature $220 \mathrm{~K}$ (no updraft) and RHI $=110 \%$ for three different contrail crystal abundances, as indicated by the lines. All curves eventually decrease because dilution of $n$ overcompensates the growth of $D$. Most of the observed contrails (open squares in Fig. 10, calculated from values in Table 2) fall into the range of the calculated $D n$ product, while all observed cirrus clouds (filled squares in Fig. 10) confirm $D_{c} n_{c}<100 \mu \mathrm{m} \mathrm{cm}^{-3}$, the latter values in agreement with other in situ observations (Ström et al. 1997) and model simulations (Lin et al. 1998). Comparison between contrail and cirrus data yields $R<1$ in all cases. Putting the parcel into an updraft region would decrease $R$ further. It is thus clear that the presence of cirrus has a very limited effect

$\leftarrow$

according to an average mixing law. Entrainment of water vapor at a fixed background humidity (as indicated) is taken into account. Ice nucleation is not included. 


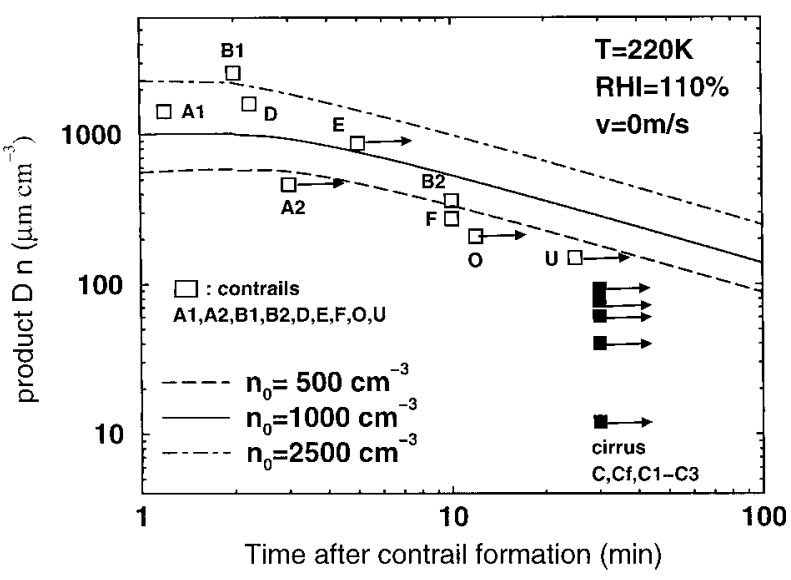

FIG. 10. Product $D n$ of ice crystal diameter and number density of contrail particles as a function of time at $T=220 \mathrm{~K}$ and $\mathrm{RHI}=$ $110 \%$ (no updraft) for different initial ice particle concentrations. This quantity is proportional to the mass growth rate $j_{w}$ of the crystals and determines the rate of $\mathrm{H}_{2} \mathrm{O}$ vapor depletion by the growing ice crystals. Open squares mark the position of the already discussed contrail cases (values taken from Table 2). Solid squares correspond to the measured cirrus cases listed in Table 2. For the parameter range and time span indicated, contrail particles remove $\mathrm{H}_{2} \mathrm{O}$ from the vapor phase faster $(2000 \geq D n \geq 100)$ than young cirrus clouds $(100 \geq$ $D_{c} n_{c}$ ). Arrows indicate the direction of a possible uncertainty, since for these cases only the minimum age could be determined.

on the growth of contrails on the timescales of about 2 h. It appears to be unlikely that preexisting cirrus can effectively deplete the $\mathrm{H}_{2} \mathrm{O}$ reservoir and prevent persistent contrails from growing, which is in agreement with the observations of the distributions A3, B3, and $\mathrm{O} 1$ shown in Fig. 8. Only older contrails (cases $\mathrm{O}$ and $\mathrm{U})$ fall somewhat below the predicted $D n$ values, possibly due to dynamically induced diffusion that is larger than assumed in the model. All findings show a reasonable consistency between data and model estimates. The situation may be different in cirrus clouds which depleted supersaturation before contrails form. This is an important way that cirrus limit the growth of contrails.

\section{Summary and conclusions}

In situ microphysical measurements of contrails and natural cirrus clouds have been performed in the upper troposphere and tropopause region during several airborne experiments over central Europe in 1996-97. Aerosol particle and ice crystal size distributions in the size range $0.01-500 \mu \mathrm{m}$ are presented, mainly comprising PMS-type optical spectrometer data, but also obtained from a Hallet replicator, from condensation nuclei counters, and from a counterflow virtual impactor.

Instrumental comparisons show that ice crystals observed in the contrail core region and in young cirrus come close to spherical shape and that measurements of forward scattering spectrometers for these cases can be regarded as reliable for both concentrations and size. Typical ice crystal concentrations and specific surface areas of fresh contrails (age $<1 \mathrm{~min}$ ) exceed a few $1000 \mathrm{~cm}^{-3}$ and $10^{4} \mu \mathrm{m}^{2} \mathrm{~cm}^{-3}$, with mean diameters around $1 \mu \mathrm{m}$. During the aging process (up to $1 \mathrm{~h}$ ) the contrail ice crystal concentrations decrease by two to three orders of magnitude (specific surface areas only by a factor of 2-3) while mean diameters increase up to about $9 \mu \mathrm{m}$, clearly demonstrating the transformation of persistent contrails into ice clouds resembling young cirrus. Observed crystal concentrations, specific surface areas, and mean crystal diameters (effective diameters) of young cirrus are typically up to $5 \mathrm{~cm}^{-3}, 2000 \mu \mathrm{m}^{2}$ $\mathrm{cm}^{-3}$, and about $10 \mu \mathrm{m}(20 \mu \mathrm{m})$; for more developed cirrus, $1-2 \mathrm{~cm}^{-3}, 2000-7000 \mu \mathrm{m}^{2} \mathrm{~cm}^{-3}$, and about 20 $\mu \mathrm{m}(>30 \mu \mathrm{m})$, respectively. All observed cirrus clouds own a distinct haze mode with at least 4 particles $\mathrm{cm}^{-3}$ in the size range between fine and coarse particle mode, supporting - together with the observed amorphous, quasi-spherical replica images of ice crystals in young cirrus - the concept of freezing haze as an important formation process of upper-tropospheric cirrus. Young cirrus and contrails aged on timescales of $1 \mathrm{~h}$ show similar crystal size distributions with mean diameters around $10 \mu \mathrm{m}$. Computations of contrail crystal growth using a simplified parcel model generally confirm these observations and identify relative humidity, updraft velocity, and crystal concentrations in fresh contrails as important parameters driving the microphysical transformation of the contrail core region into a young cirrus cloud. They also suggest that contrail growth should only be weakly affected by the presence of a cirrus cloud.

The experiments suggest that a more detailed resolution of the small-scale microphysical and dynamic structures related to contrail growth are hard to achieve by in situ measurements bound to a fast moving measuring platform like a jet aircraft. Poor sampling statistics for larger ice crystals, limited visibility at the site, and the difficulty in determining the sampling position within the corkscrew-shaped trail are three examples of experimental limitations. Radiative measurements below, inside, and aloft contrails often require much more stable and homogeneous conditions than those commonly achieved in practice.

A promising concept for future airborne experiments should aim at a more systematic investigation of larger cirrus cloud fields to answer the question of if and to what extent current and future aviation influences the formation of new, or alters the properties of existing, cirrus clouds in the tropopause region. Such a concept presumes detailed knowledge of the meteorological history of the air masses involved, including weather forecasting and back-trajectory calculations. Systematic sampling of larger cloud fields will be easier to compare with satellite radiative information and will be more representative for average impacts (and variability) of 
aged contrails or contrail-induced cirrus clouds on radiation (compared to natural cirrus clouds).

Acknowledgments. We thank the pilots and the staff of the DLR Flight Department for essential contributions to many successful scientific flights; and C. Rox, H. Horst, J. Demmel, and H. G. Krafczyk for many weeks of excellent technical support. We are grateful for fruitful discussions with R. Busen and U. Schumann. Thanks also for the ambitious work of the reviewers, in particular D. Baumgardner. The various scientific programs mentioned have been supported by grants of the German Secretary of Education and Research and the European Commission.

\section{REFERENCES}

Anderson, T. L., R. J. Charlson, and D. S. Covert, 1993: Calibration of a counerflow virtual impactor at aerodynamic diameters from 1 to $15 \mu \mathrm{m}$. Aerosol Sci. Technol., 19, 317-329.

Baumgardner, D., and M. Spowart, 1990: Evaluation of the Forward Scattering Spectrometer Probe. Part III: Time response and laser inhomogeneity limitations. J. Atmos. Oceanic Technol., 7, 666672.

_ , and A. Korolev, 1997: Airspeed corrections for optical array probe sample volumes. J. Atmos. Oceanic Technol., 14, 1224 1229 .

— , and B. Gandrud, 1998: A comparison of the microphysical and optical properties of particles in an aircraft contrail and mountain wave cloud. Geophys. Res. Lett., 25, 1129-1132.

- W. Strapp, and J. E. Dye, 1985: Evaluation of the Forward Scattering Spectrometer Probe. Part II: Corrections for coincidence and dead-time losses. J. Atmos. Oceanic Technol., 2, 626632 .

— J. E. Dye, B. W. Gandrud, and R. G. Knollenberg, 1992: Interpretation of measurements made by the forward scattering spectrometer probe (FSSP-300) during the Airborne Arctic Stratospheric Expedition. J. Geophys. Res., 97, 8035-8046.

,,,--- K. Barr, K. Kelly, and K. R. Chan, 1996: Refractive indices of aerosols in the upper troposphere and lower stratosphere. Geophys. Res. Lett., 23, 749-752.

—, R. C. Miake-Lye, M. R. Anderson, and R. C. Brown, 1998: An evaluation of temperature, water vapor, and vertical velocity structure of aircraft contrails. J. Geophys. Res., 103 (D8), 8727 8736

Borrmann, S., S. Solomon, J. E. Dye, and B. Luo, 1996: The potential of cirrus clouds for heterogeneous chlorine activation. Geophys. Res. Lett., 23, 2133-2136.

Brasseur, G. P., and Coauthors, 1998: The atmospheric effects of aircraft emissions. Scientific assessment on behalf of the European Commission. Atmos. Environ., 32, 2329-2418.

Brenguier, J. L., 1989: Coincidence and dead-time corrections for particle counters. Part II: High concentration measurements with a FSSP. J. Atmos. Oceanic Technol., 6, 585-598.

- D. Baumgardner, and B. Baker, 1994: A review and discussion of processing algorithms for FSSP concentration measurements. J. Atmos. Oceanic Technol., 11, 1409-1414.

Busen, R., R. Baumann, A. Petzold, F. Schröder, and U. Schumann, 1997: Aircraft measurements on the formulation and dilution of contrails. DLR-Mitt. 97-04, 11 pp. [Available from reinhold. busen@dlr.de]

Cooper, W. A., 1988: Effects of coincidence on measurements with a forward scattering spectrometer probe. J. Atmos. Oceanic Technol., 5, 823-832.

Crepel, O., J.-F. Gayet, J.-F. Fournol, and S. Oshchepkov, 1997: A new airborne Polar Nephelometer for the measurement of optical and microphysical cloud propperties. Part II: Prelimminary tests. Ann. Geophys., 15, 460-470.

Crutzen, P. J., and V. Ramanathan, 1996: Clouds, Chemistry, and Climate: Global Environmental Change. NATO ASI Series I, Vol. 35, Springer-Verlag, $130 \mathrm{pp}$.

DeMott, P. J., M. P. Meyers, and W. R. Cotton, 1994: Parameterization and impact of ice initiation processes relevant to numerical simulations of cirrus clouds. J. Atmos. Sci., 51, 77-90.

- D. C. Rogers, and S. M. Kreidenweis, 1997: The susceptibility of ice formation in upper tropospheric clouds to insoluble aerosol components. J. Geophys. Res., 102, 19 575-19 584.

Duroure, C., H. R. Larsen, H. Isaka, and P. Personne, 1994: 2D image population analysis. J. Rech. Atmos., 34, 195-205.

Friedl, R. R., Ed., 1997: Atmospheric effects of subsonic aircraft. Interim Assessment Rep., Advanced Subsonic Technology Program, NASA Ref. Publ. 1400, 168 pp. [Available from Hans.Schlager@dlr.de or Franz.Schröder@dlr.de]

Freudenthaler, V., F. Homburg, and H. Jäger, 1995: Contrail observations by ground-based scanning lidar: Cross-sectional growth. Geophys. Res. Lett., 22, 3501-3504.

Fu, Q., and K. N. Liou, 1993: Parameterization of radiative properties of cirrus clouds. J. Atmos. Sci., 50, 2008-2019.

Gayet, J.-F., P. R. Brown, and F. Albers, 1993: A comparison on incloud measurements obtained with six PMS 2D-C probes. $J$. Atmos. Oceanic Technol., 10, 180-194.

— G. Febvre, and H. Larsen, 1996: The reliability of the PMS FSSP in the presence of small ice crystals. J. Atmos. Oceanic Technol., 13, 1300-1310.

_ _ and Coauthors, 1998: In situ measurements of the scattering phase function of stratocumulus, contrails and cirrus. Geophys. Res. Lett., 25, 991-994.

Gerz, T., and F. Holzäpfel, 1999: Wingtip vortices, turbulence, and the distribution of emissions. AIAA J., 37 (10), 1270-1276.

, T. Dürbeck, and P. Konopka, 1998: Transport and effective diffusion of aircraft emissions. J. Geophys. Res., 103, 25 90525913.

Gierens, K., 1996: Numerical simulations of persistent contrails. $J$. Atmos. Sci., 53, 3333-3348.

_ - and E. Jensen, 1998: A numerical study of the contrail-to-cirrus transition. Geophys. Res. Lett., 25, 4341-4344.

Goodman, J., R. F. Pueschel, E. J. Jensen, S. Yerma, G. V. Ferry, S. D. Howard, S. A. Kinne, and D. Baumgardner, 1998: Shape and size of contrails ice particles. Geophys. Res. Lett., 25, 13271330.

Hallet, J., 1976: Measurement of size, concentration and structure of atmospheric particulates by the airborne continuous particle replicator. Desert Research Institute Rep. AFGL-TR-76-0149, 92 pp. [Available from Peter.Wendling@dlr.de]

Heymsfield, A. J., and R. M. Sabin, 1989: Cirrus crystal nucleation by homogenous freezing of solution droplets. J. Atmos. Sci., 46, $2252-2264$.

- and L. M. Miloshevich, 1993: Homogenous ice nucleation and supercooled liquid water in orographic wave clouds. J. Atmos. Sci., 50, 2335-2353.

, and G. M. McFarquhar, 1996: High albedos of cirrus in the tropical Pacific warm pool: Microphysical interpretations from CEPEX and from Kwajalein, Marshall Islands. J. Atmos. Sci., 53, 2424-2451.

- L. L. Miloshevich, C. Twohy, G. Sachse, and S. Ottmans, 1998a: Upper tropospheric relative humidity observations and implications for cirrus ice nucleation. Geophys. Res. Lett., 25, 1343-1346.

_ R. P. Lawson, and G. W. Sachse, 1998b: Growth of ice crystals in a precipitating contrail. Geophys. Res. Lett., 25, 1335-1338.

Jensen, E. J., and O. B. Toon, 1997: The potential impact of soot particles from aircraft exhaust on cirrus clouds. Geophys. Res. Lett., 24, 249-252.

_ - D. D. Westphal, S. Kinne, and A. Heymsfield, 1994: Microphysical modeling of Cirrus 1: Comparison with 1986 FIRE IFO Measurements. J. Geophys. Res., 99, 10 421-10 442. 
and Coauthors, 1998: Environmental conditions required for contrail formation and persistence. J. Geophys. Res., 103, 39293936.

Kärcher, B., Th. Peter, U. M. Biermann, and U. Schumann, 1996: The initial composition of jet condensation trails. J. Atmos. Sci., 53, 3066-3083.

—, R. Busen, A. Petzold, F. P. Schröder, U. Schumann, and E. J. Jensen, 1998: Physicochemistry of aircraft-generated liquid aerosols, soot, and ice particles. Part 2: Comparison with observations and sensitivity studies. J. Geophys. Res., 103 (D14), 17 129-17 147.

Knollenberg, R. G., 1970: The optical array: An alternative to scattering or extinction for airborne particle size determination. $J$. Appl. Meteor., 9, 86-103.

Korolev, A. V., S. V. Kusnetsov, Y. E. Makarov, and V. S. Novikov, 1991: Evaluation of measurements of particle size and sample area from optical array probes. J. Atmos. Oceanic Technol., 8, $514-522$.

— J. W. Strapp, and G. A. Isaac, 1998: Evaluation of the accuracy of PMS optical array probes. J. Atmos. Oceanic Technol., 15, $708-720$.

Kuhn, M., A. Petzold, D. Baumgardner, and F. Schröder, 1998: Particle composition of a young condensation trail and of upper tropospheric aerosol. Geophys. Res. Lett., 25, 2679-2682.

Larsen, H., J.-F. Gayet, G. Febvre, H. Chepfer, and G. Broniez, 1998: Measurement errors in cirrus cloud microphysical properties. Ann. Geophys., 16, 266-276.

Lawson, R. P., A. Heymsfield, S. M. Aulenbach, and T. L. Jensen, 1998: Shapes, sizes and light scattering properties of ice crystals in cirrus and a persistent contrail during SUCCESS. Geophys. Res. Lett., 25, 1331-1334.

Lin, H., K. J. Noone, J. Ström, and A. J. Heymsfield, 1998: Small ice crystals in cirrus clouds: A model study and comparison with in situ observations. J. Atmos. Sci., 55, 1928-1939.

Mannstein, H., R. Meyer, and P. Wendling, 1999: Operational detection of contrails from NOAA-AVHRR-data. Int. J. Remote Sens., 20, 1641-1660.

Mertes, S., F. Schröder, and A. Wiedensohler, 1995: The particle detection efficiency curve of the TSI-3010 CPC as a function of the temperature difference between saturator and condenser. Aerosol Sci. Technol., 23, 257-261.

Minnis, P., D. F. Young, D. P. Garber, I. Nguyen, W. L. Smith Jr., and R. Palikonda, 1998: Transformation of contrails into cirrus during SUCCESS. Geophys. Res. Lett., 25, 1157-1160.

Noone, K. B., J. A. Ogren, J. Heintzenberg, R. J. Charlson, and D. S. Covert, 1985: Design and calibration of a counterflow virtual impactor for sampling of atmospheric fog and cloud droplets. Aerosol Sci. Technol., 8, 235-244.

—, K. J. Noone, J. Heintzenberg, J. Ström, and J. Ogren, 1993: In situ observations of cirrus cloud microphysical properties using the Counterflow Virtual Impactor. J. Atmos. Oceanic Technol., 10, 294-303.

Petzold, A., and Coauthors, 1997: Near field measurements on con- trail properties from fuels with different sulfur content. J. Geophys. Res., 102, 29 867-29 880.

Platt, C. M. R., and J. D. Spinhirne, 1989: Optical and microphysical properties of cold cirrus clouds: Evidence for regions of small ice particles. J. Geophys. Res., 94, 11 151-11 164.

Pruppacher, H. R., and J. D. Klett, 1978: Microphysics of Clouds and Precipitation. D. Reidel, 714 pp.

Sassen, K., and G. C. Dodd, 1989: Haze particles nucleation simulations in cirrus clouds, and applications for numerical modeling and lidar studies. J. Atmos. Sci., 46, 3005-3014.

Schröder, F., and J. Ström, 1997: Aircraft measurements of sub micrometer aerosol particles $(>7 \mathrm{~nm})$ in the midlatitude free troposphere and tropopause region. Atmos. Res., 44, 333-356.

— B. Kärcher, A. Petzold, R. Baumann, R. Busen, C. Höll, and U. Schumann, 1998: Ultrafine aerosol particles in aircraft plumes: In situ observations. Geophys. Res. Lett., 25, 27892792.

Schumann, U., 1996: On conditions for contrail formation from aircraft exhaust. Meteor. Z., 5, 4-23.

_ Ed., 1997: Pollution from aircraft emissions in the North Atlantic flight corridor (POLINAT). European Commision ECSCEC-EAEC, Brussels, Belgium, 303 pp. [Available from ulrich. schumann@dlr.de]

—_, and P. Wendling, 1990: Air Traffic and the Environment-Background, Tendencies and Potential Global Atmospheric Effects. Springer-Verlag, $245 \mathrm{pp}$.

- H. Schlager, F. Arnold, R. Baumann, P. Haschberger, and O. Klemm, 1998: Dilution of aircraft exhaust plumes at cruise altitudes. Atmos. Environ., 32, 3097-3103.

Seinfeld, J. H., and S. N. Pandis, 1997: Atmospheric Chemistry and Physics. John Wiley and Sons, $1326 \mathrm{pp}$.

Spinhirne, J. D., W. D. Hart, and D. P. Duda, 1998: Evolution of the morphology and microphysics of contrail cirrus from airborne remote sensing. Geophys. Res. Lett., 25, 1153-1156.

Starr, D. O., and S. Cox, 1985: Cirrus clouds. Part I: A cirrus cloud model. J. Atmos. Sci., 42, 2663-2681.

Strapp, J. W., W. R. Leaitch, and P. S. K. Liu, 1992: Hydrated and dried aerosol-size-distribution measurements from the Particle Measurement Systems FSSP-300 probe and the deiced PCASP100X probe. J. Atmos. Oceanic Technol., 9, 548-555.

Ström, J., and J. Heintzenberg, 1994: Water vapor, condensed water, and crystal concentration in orographically influenced cirrus clouds. J. Atmos Sci., 51, 2368-2383.

,-- , K. J. Noone, K. B. Noone, J. A. Ogren, F. Albers, and M. Quante, 1994: Small crystals in cirrus clouds clouds: A case study of residue size distribution, cloud water content and related cloud properties. Atmos. Res., 32, 125-141.

- B. Btrauss, T. Anderson, F. Schröder, J. Heintzenberg, and P. Wendling, 1997: In situ observations of the microphysical properties of young cirrus clouds. J. Atmos. Sci., 54, 2542-2553.

Wendisch, M., A. Keil, and A. V. Korolev, 1996: FSSP characterization with monodisperse water droplets, J. Atmos. Oceanic Technol., 13, 1152-1165. 